\title{
Política y políticas en materia de justicia: Apuntes de un observador-participante ${ }^{1}$
}

\author{
Josep M. Vallès \\ Universitat Autònoma de Barcelona \\ jm.valles@uab.es
}

\begin{abstract}
Resumen
Desde una perspectiva no académica de observación participante, el texto describe la gestión de las políticas emprendidas por el Departamento de Justicia de la Generalitat de Cataluña, del cual el autor fue titular durante los años del gobierno presidido por P. Maragall (2003-2006). De esta forma, se pone de relieve la complejidad de un escenario singular por razón tanto de las materias objeto de la gestión, como por las características del marco gubernamental e intergubernamental del momento. El enfoque utilizado saca a la luz aspectos, factores y comportamientos que raramente se incorporan a los análisis politológicos "clásicos". El presente texto constituye una versión resumida de un capítulo del libro publicado en catalán por el autor en 2008.
\end{abstract}

Palabras clave Generalitat de Cataluña, gestión y administración de la justicia, política judicial, política penal, política penitenciaria, política catalana, relaciones intergubernamentales.

\section{Judicial and Prisons Policies and Politics: A Participant Observer's Account}

\begin{abstract}
From a non academic perspective of participant observation, the author describes a set of policies undertaken by the Justice Department of Catalonia's Generalitat, which he led during the years of President Maragall's government (2003-2006). With this insight, the text highlights the complexity of the unique scenario resulting not only from the policies implemented, but also from the characteristics of both the governmental and the inter-governmental framework of the period. This approach shows key aspects, factors and actions which are rarely introduced into "classical" political analyses. This text is an abridged version of a book's chapter published by the author in 2008.

Keywords

Catalonia's Generalitat, judicial policy, prisons policy, criminal policy, judicial administration and management, Catalan politics, inter-governmental relations.
\end{abstract}

1 Traducción del catalán de Santiago Garre Pelegrina. 


\section{NOTA INTRODUCTORIA DEL AUTOR}

Tras siete años de intervención en la política institucional (1999-2006), consideré oportuno dejar constancia escrita de las impresiones de un profesor de ciencia política y de la administración temporalmente comprometido en la acción política (Vallès, 2008). No pretendía elaborar una crónica de hechos ni un estudio académico. Me limité a exponer unas reflexiones personales a modo de observador-participante de la vida política catalana, dedicando sendos capítulos al proyecto político del presidente Maragall, a la dinámica parlamentaria, al proyecto de nuevo Estatuto o a la relación con los medios de comunicación. Aquíse reproduce un extracto del capítulo 6 de la obra. Corresponde a la descripción del trabajo desarrollado como miembro del Ejecutivo catalán y titular del Departamento de Justicia de la Generalitat ${ }^{2}$. Entre las políticas que dicho Departamento debe definir y ejecutar figuran el apoyo a la administración de justicia y la gestión de los servicios penitenciarios. Sin pretensiones de estudio académico, el texto contiene un diagnóstico de la situación en ambos campos y una exposición de las políticas puestas en marcha durante el período ${ }^{3}$. El profesor Francisco J. Vanaclocha, director de la revista GAPP, colega y amigo, ha considerado que la difusión de este texto podría ser de interés para los lectores. Aprecio su optimismo y confío en que no se vea del todo defraudado.

\section{DESDE LA CONSEJERÍA DE JUSTICIA: A FAVOR DEL SERVICIO PÚBLICO}

\section{Una consejería más importante que codiciada}

Nunca se me ocurrió que -en una fase tan avanzada de mi trayectoria profesional- iba a formar parte del gobierno de Cataluña (el Govern). En algún debate parlamentario, mis antagonistas en la oposición me reprocharon que aparentara no encontrarme "a gusto" en el Departamento. Tenían parte de razón. Pero por motivos distintos a los que imaginaban. Porque para mí ser consejero no era una cuestión de "gusto", sino de compromiso con el servicio público. Algo quizá difícil de entender para quienes ocupar una consejería -o cualquier otro cargo público- constituye un deseo de realización personal, un deseo que no todo el mundo experimenta. Tampo-

2 Una descripción detallada y ordenada de las actuaciones del Departamento de Justicia durante el período se encuentra en la obra editada por la Generalitat: Trenta mesos d'acció de govern (2005). No es, por tanto, objeto de este texto desarrollar de manera sistemática una concepción de lo que podría ser una administración de justicia que combinara adecuadamente su naturaleza de poder político democrático, su carácter de servicio público esencial y su articulación en un Estado compuesto y no unitario. Es decir, una concepción muy alejada de la realidad que ofrece la actual administración de justicia en España.

3 El desarrollo de las propuestas para una nueva política judicial en Cataluña figura en el Llibre Verd de l'Administració de Justícia a Catalunya publicado por el Departamento de Justicia (2005). Con todo, buena parte de las expectativas depositadas en el Estatuto de 2006 para avanzar en la modernización del servicio público de la justicia han quedado congeladas por la Sentencia 31/2010 del Tribunal Constitucional que anuló disposiciones estatutarias sobre la materia, interpretó otras de manera restrictiva y remitió algunas a una futura normativa estatal. Para un análisis crítico de este punto de la sentencia, véanse los traba134 tas de Aparicio Pérez (2010) y Cabellos Espiérrez (2010) publicados en el número especial dedicado a la ci- 
co lo experimenta la totalidad de quienes optamos por un compromiso político que podemos satisfacer sin ansias irresistibles de ocupar una posición institucional.

En todo caso, tenía muy clara la importancia del Departamento de Justicia, el único de cualquier gobierno -como señalé en público en algunas ocasiones- que tiene nombre de virtud. Bromas aparte, su influencia es difícil de percibir para el público y para buena parte de la clase política que lo considera a menudo de "segunda clase". Puede ser que ésta sea la explicación de que hubiera sido uno de los otorgados sistemáticamente y durante más de veinte años a Unió Democràtica(UDC), el socio menor de la coalición Convergència i Unió( $\mathrm{CiU})$. Y quizás también por este motivo, la decisión de Maragall de confiarlo a un excéntrico de la política como yo no fue nunca impugnada públicamente por parte de los demás socios del tripartito.

¿Con qué bagaje llegaba al Departamento? Contaba con una licenciatura y un doctorado en derecho que me habían servido para entender que -en los sistemas democráticos- el derecho es un instrumento del poder para gestionar los conflictos colectivos. Y que también debe funcionar como el dispositivo que refrene los excesos del propio poder. Lo había aprendido de algunos profesores y de mi propia experiencia como docente universitario. Añadiré que no consideraba ningún handicap especial el hecho de no haber practicado profesiones directamente vinculadas con la justicia, como la magistratura o la abogacía. Lo más importante -pensaba- no es tener las respuestas a todas las preguntas, sino saber cuáles son las preguntas que es menester plantearse y a quién dirigirlas. Por lo mismo, no creo indispensable proceder del gremio o sector para ser responsable político de un determinado ámbito gubernamental. Esto puede conllevar algún inconveniente inicial en cuanto al conocimiento de algunos rudimentos de la materia, cosa que se resuelve con buenos colaboradores. En cambio, antecedentes profesionales en el mismo sector pueden implicar a veces la prevalencia de tics y compromisos corporativos que limitan la necesaria libertad de criterio y de acción. Con todo, la problemática con la que habría de enfrentarme no me era del todo desconocida. Y no solamente por contactos personales o universitarios. Gracias al gobierno alternativo de Maragall y desde la oposición parlamentaria, había analizado -junto con el diputado Alex Masllorens- las políticas de justicia y derecho durante la legislatura de 1999-2003, preparando propuestas para su renovación. Con las insuficiencias propias de la falta de información detallada, las líneas básicas de aquellas propuestas fueron útiles en el momento de dibujar las nuevas políticas del Departamento.

También llegaba al Govern con una vocación por la gestión en el servicio público: esta vocación me había conducido a descartar el ejercicio de la abogacía, a pesar de admirar a algunos compañeros de facultad que la practicaban. La afición a la gestión pública la había satisfecho en cargos de dirección universitaria y en otras iniciativas sociales de carácter no lucrativo. En esta línea, siempre había preferido "hacer cosas" a "hacer de algo". Lo cual se tradujo probablemente en mi dedicación desigual a las distintas exigencias del oficio de consejero, en el que pesó bastante más la faceta gestora que la representativa o protocolaria. 
Finalmente y en esta línea, debo apuntar que mi intención era abordar la dedicación al Departamento con el impulso transformador de una agenda de cambio y no con la prudencia engañosa de un cómodo "ir tirando". Esta fidelidad al proyecto de cambio de Maragall incluía también la condición que me había autoimpuesto: la de durar como consejero -si el presidente no me cesaba antes- no más de una legislatura. Ser miembro de un gobierno sin aspirar a hacer carrera política era una situación singular, con más riesgo, pero también con más libertad. En todo caso, asumía la responsabilidad con el realismo de una edad que ya te ha enseñado que no todo es posible. Pero con la conciencia -como apuntó Max Weber- que solo se logra aquello que es posible si se intenta día tras día aquello que parece imposible.

\section{Crear un equipo con ganas de cambiar las cosas}

No es un hecho conocido que el Departamento de Justicia se encontraba entre los más voluminosos del Govern en nómina de personal y en cuota presupuestaria. Me había provisto con un cuadro básico de objetivos a perseguir, extraídos del análisis realizado desde la oposición sobre las carencias detectadas. Pero también había aprendido de otras experiencias personales que uno de los factores determinantes del acierto de una gestión no es tanto la propia capacidad individual, como la habilidad para escoger un buen equipo de colaboradores directivos. Es una regla elemental de toda gran organización. Una política bien definida no es más que una hoja de papel si no se dispone de un equipo directivo competente y comprometido. Por ello, mi primera preocupación era la selección de este equipo.

¿Qué perfil me parecía necesario para formar este equipo? Consideraba obligadas tres condiciones: una cierta experiencia en alguna de las administraciones públicas del país, una orientación política progresista que no tenía que ir forzosamente ligada a ninguna vinculación partidista y finalmente la valentía inteligente para poner en marcha iniciativas de renovación del Departamento. Quería que quienes me acompañaran compartieran la voluntad de cambio y no fueran aficionados al "ir tirando" propio de los que se preocupan sobre todo por su supervivencia en la carrera política. Tuve libertad absoluta para construir este equipo sin presiones de partido ${ }^{4}$.

Hago constar también que mis invitaciones a colaborar tuvieron -prácticamente en todos los casos- una respuesta favorable inmediata por parte de los invitados. No les prometía una tarea fácil ni especialmente gratificante para una carrera profesional: es de dominio público que las competencias gestionadas por el Departamento no

4 Las dos secretarías y las seis direcciones generales fueron confiadas a personas con experiencia en dirección de organismos públicos o pertenecientes a cuerpos de la administración autonómica o estatal. Corrigiendo la tradición de nombramientos de libre designación, los delegados territoriales fueron seleccionados por concurso público entre funcionarios de cualquier administración, estatal, autonó136 mica o local. Formaron parte del gabinete del conseller cuatro personas de libre designación, con dedica- 
se encuentran entre las más rentables desde el punto de vista de la carrera política o profesional. Pero el hecho de encontrar esta reacción positiva me demostraba que había identificado a personas con vocación de servicio público, dispuestas a dedicarse a objetivos poco vistosos pero que también reputaban como esenciales para el buen funcionamiento de un estado social y democrático de derecho. Este grupo de colaboradores directos era la pieza esencial para todo lo que convenía poner en marcha. Quiero reconocer públicamente la dedicación de todos ellos.

Pero los cargos de confianza designados por el consejero solo eran una parte muy reducida de los efectivos personales del Departamento. Integraban la plantilla un centenar de directivos y más de diez mil empleados públicos: funcionarios, contratados o interinos. Todos ellos recibieron el mensaje de que se valoraría su competencia y dedicación, y no sus antecedentes políticos o de partido. En los primero contactos -colectivos o individuales- con ellos, dejé claras tres cosas: que el personal es el activo principal en una organización de servicios, que ellos eran profesionales permanentes de los cuales la ciudadanía esperaba una dedicación competente y que era función del consejero y su equipo político marcar las estrategias básicas y asegurar su cumplimiento. En correspondencia a mi respeto a su condición de profesionales de la administración pública, esperaba de ellos lealtad y colaboración con un gobierno y un consejero que habían recibido democráticamente la misión de gobernar el país. También subrayaba que el carácter de "temporeros" que tienen todos los gobernantes democráticos no debe equipararse con la condición de "intrusos" que algunos atribuían al gobierno de Maragall al negarle legitimidad. Por mi parte, estaba claro que rechazaba toda tentación de "apropiación" personal o partidista del Departamento. Pero también hacía constar que venía dispuesto a dirigirlo con toda la autoridad que se me había conferido democráticamente.

\section{Una plantilla numerosa, un personal sin dirección}

El Departamento contaba -como he dicho- con una plantilla muy abundante y muy heterogénea. En el momento de asumir su dirección, el Departamento de Justicia era el cuarto en efectivos personales detrás de Salud, Educación e Interior. Es conocida la prevención de la opinión pública contra los funcionarios y, en general, contra todos los empleados públicos. Creo que es una prevención poco fundada en lo que concierne al conjunto de la calidad de las personas que forman este colectivo. Pero creo también que es un prejuicio fundamentado en lo que se refiere a la estructura y organización que los encuadra y en la cual deben trabajar. Puedo afirmarlo con conocimiento de causa, como funcionario con muchos trienios a mis espaldas.

Dije antes que en una organización de servicios personales como es el Departamento de Justicia el activo principal lo constituyen sus efectivos humanos: su competencia técnica, la actitud de servicio al ciudadano, la disposición a rendir cuentas de su trabajo a la ciudadanía que les retribuye económicamente. Corresponde al personal directivo reforzar estas disposiciones por la vía de la formación, de la exigencia y del 
ejemplo. Porque es sabido que en un contingente tan numeroso coexisten -en proporciones distintas- los individuos vocacionales y entregados a sus funciones, un amplio sector capaz de acomodarse al ritmo dominante $y$, finalmente, un residuo rémora que es necesario soportar, aislar y, si se puede, reducir al mínimo. Esta situación propia de todo gran colectivo era también perceptible en el personal del Departamento.

He querido empezar con la referencia a las poco lucidas cuestiones de personal porque me parecieron y me parecen esenciales para el acierto de cualquier política pública. Disponer de una buena definición de objetivos y de una apropiada dotación presupuestaria es imprescindible. Pero no serán suficientes si no se dispone de los efectivos humanos adecuados para gestionarlos.

\section{Empezar por los fundamentos de un buen servicio público}

¿Qué políticas y qué servicios tiene que gestionar el Departamento de Justicia? Le corresponde el apoyo a la administración de justicia, la gestión de los servicios penitenciarios, de rehabilitación y de justicia juvenil, el despliegue y la difusión del derecho civil catalán y el fomento y la garantía de los derechos de asociación y fundación. Son políticas derivadas de la distribución competencial marcada por la Constitución y el Estatuto -en aquel momento el Estatuto de 1979-. Son funciones de poca espectacularidad, pero con trascendencia para la calidad del Estado democrático de derecho. Es decir, para garantizar a los ciudadanos que sus derechos se encuentren protegidos de manera razonablemente satisfactoria.

Resumo los puntos esenciales:

- Era ineludible atender de manera preferente a las cuestiones de personal saneando una situación lastrada por la inexistencia de planificación, por una anómala gestión administrativa, por un exceso de interinidad y por la ausencia de un sistema ordenado de selección, formación, incentivos y gestión de carrera. Era preciso introducir la cultura de la responsabilidad directiva entre el personal, si queríamos una organización capaz de responder con iniciativa e imaginación a las exigencias sociales. Tales actuaciones debían definirse tras haber dialogado con la representación sindical de los empleados y haber manifestado nuestra buena disposición al entendimiento. Pero también convenía dejar claro que no se llegaría a ningún acuerdo laboral a costa de la calidad del servicio público y en perjuicio de los ciudadanos, tal como había sucedido en el pasado en más de una ocasión.

- Era imperativo respetar escrupulosamente la normativa presupuestaria y desterrar prácticas irregulares o confusas que habían servido para esconder la incapacidad de gestión de los recursos disponibles. Después de informar al Govern y al Parlament, se estableció -de acuerdo con el Departamento de 138 Economía y Finanzas- un cálculo más afinado de las necesidades presupues- 
tarias de la consejería, con un plan diseñado para eliminar gradualmente el déficit detectado. El plazo de este plan era de cuatro años, pero pudo llevarse a cabo prácticamente en tres, gracias al sistema de control introducido y a la buena respuesta de los directivos responsables. De este modo quedaba claro que -si se presupuestaba de manera ajustada y se ejecutaba el presupuesto disciplinadamente- podían cumplirse los objetivos establecidos y a la vez resolver la situación negativa recibida del Govern anterior.

- Era obligado definir con rigor y ejecutar un programa inversor potente para resolver las deficiencias históricas muy graves. En pocos meses, establecimos un inventario urgente de las carencias judiciales y penitenciarias y quedó clara la magnitud del reto: por lo que respecta al volumen que era necesario edificar, a su coste financiero y al ritmo necesario. La situación de gran parte del parque inmobiliario de la justicia y de prisiones era deplorable, después de años de imprevisión. De acuerdo con el Departamento de Economía y Finanzas, se programaron las exigencias presupuestarias de un plan inversor sin precedentes en la historia del Departamento de Justicia. Se pusieron en marcha las licitaciones, la adjudicación y el inicio de la ejecución. Durante 2007 se llevaron a cabo las primeras inauguraciones de equipamientos que continuarían hasta 2010-2011.

- En una administración con extensa implantación territorial, se imponía una desconcentración de la capacidad de decisión. Las direcciones territoriales existentes eran débiles en dotación y limitadas en su ámbito decisor. Mi punto de vista era que los criterios de proximidad y subsidiariedad que el "proyecto del cambio" había incorporado en su programa debían aplicarse también a la administración de la Generalitat y, en particular, a un Departamento como el de Justicia. No era esta la tradición del Departamento ni de la administración de la Generalitat en su conjunto, centralizada en exceso. Para corregirla, convenía reforzar las direcciones territoriales, transfiriéndole más competencias y capacidad de ejecución presupuestaria y seleccionando adecuadamente a sus responsables.

- Finalmente, era imprescindible tener presente la importancia de las tecnologías de la información y la comunicación en una gran organización de servicios. Nos sorprendió -a mí y a todos los que nos incorporamos al Departamento- el retraso de la infraestructura informática general y en la administración de justicia. Ni la red, ni los equipos, ni las bases de datos, ni las aplicaciones empleadas aprovechaban las posibilidades tecnológicas existentes. Se puso en marcha la substitución de toda la infraestructura hard que se completó (2004-2005). Se inició la elaboración de nuevos programas y la integración de bases de datos, que debían posibilitar una gestión más eficiente y más transparente. Ello explica que -a la dificultad técnica- se añadieran también resistencias de los que veían con poco entusiasmo y con cierto temor la transparencia y el control de rendimientos que comportaba la introducción de tales tecnologías. 
Estas líneas estratégicas orientaron las actuaciones en cada uno de los ámbitos del Departamento. Se concretaron en un plan de trabajo y en una valoración periódica del grado de consecución de los objetivos que el consejo de dirección del Departamento revisaba en sus reuniones. El consejo se reunía regularmente con una periodicidad quincenal. Con la misma periodicidad, despachaba yo individualmente con los secretarios generales y de servicios penitenciarios y con todos los directores generales. Este contacto personal me era muy útil para seguimiento y previsión de las principales incidencias en la aplicación de las políticas sectoriales. Pero también para captar impresiones y estados de ánimo que no se manifestaban tan claramente en los encuentros colectivos.

Fue de mucha ayuda difundir aquellas líneas estratégicas entre todos los funcionarios con responsabilidad directiva. Con este objetivo, fueron convocados a reuniones periódicas. La primera se celebró pocas semanas después de mi toma de posesión. Era una novedad -según se me informó en aquel entonces- que el centenar de personas con cargos directivos del Departamento compartieran unas horas e intercambiaran experiencias y propuestas con el consejero y su equipo. Resultaba sorprendente que se hubiera tardado tantos años en hacer uso de una herramienta elemental para cohesionar los trabajos del Departamento. Porque es casi una obviedad que estos encuentros son -sin mitificar su influencia- una buena herramienta para comprometer a todo el cuadro directivo en la orientación y en la eficiencia del servicio que la ciudadanía nos había encargado. Según los comentarios recogidos en aquellas reuniones, deduzco que esta relación directa fue positiva para la gran mayoría de los directivos. $Y$, en definitiva, para la calidad de la tarea realizada entre todos durante aquellos años.

Era obligado rendir cuentas a la ciudadanía del planteamiento y de la ejecución del programa trazado. Eran destinatarios el Parlament, como expresión de la voluntad política nacional, los partidos que daban su apoyo al Govern, los ámbitos profesionales o ciudadanos relacionados con las temáticas propias del Departamento y, finalmente, los medios de comunicación como instrumento de contacto con la opinión pública. Sobre las relaciones con el Parlament, ya he expresado mi opinión escéptica respecto de las posibilidades actuales de la institución y la manera con la que los grupos parlamentarios las explotan. Como dije antes, el formato de los debates parlamentarios no facilita un intercambio constructivo que permita intercambiar la crítica y la propuesta. Tampoco en las comisiones. En la Comisión de Justicia y Derecho, lo intenté con exposiciones detalladas de nuestras políticas. Pero encontré una oposición oportunista y superficial, incapaz de plantear un debate riguroso sobre las políticas en marcha o de proponer alternativas a las mismas.

En las relaciones con las formaciones políticas de la mayoría, facilité información periódica a mi grupo parlamentario Socialistes-Ciutadans pel Canvi(PSC-CpC), ya fuera a instancia mía o por solicitud de miembros del grupo. Igualmente lo hice con los portavoces correspondientes de Esquerra Republicana de Catalunya (ERC) y de Inicia140 tiva els Verds per Catalunya-Esquerra Unida (ICV-EUiA), socios de la mayoría de gobier- 
no. En cuanto a los ámbitos profesionales, sociales y ciudadanos, me pareció muy importante implicarlos más en el debate sobre la situación de la administración de justicia y de la administración penitenciaria, facilitándoles información sobre situaciones muy desconocidas por actores sociales que podrían desarrollar un rol positivo de impulso renovador. Asistí a encuentros, conferencias o comidas, a veces a petición de parte o por iniciativa propia. Creo en este ejercicio de contacto directo con sectores profesionales y ciudadanos para comprometerlos en el trato de una temática de la cual suelen tener una percepción insuficiente o sesgada. Finalmente, la difícil relación con los medios de comunicación se rigió por los criterios que expongo con más detaIles en otro capítulo. En conjunto, creo que el esfuerzo por comunicar y explicar todas las políticas confiadas al Departamento fue intenso y con resultados bastante positivos, si atiendo a la colaboración obtenida por parte de diversos actores privados e institucionales, y no únicamente a las muestras de aprobación o desaprobación suscitadas por nuestra actividad.

\section{LA ADMINISTRACIÓN DE JUSTICIA: ¿PODER DEMOCRÁTICO? ¿SERVICIO PÚBLICO?}

Diez mil personas aproximadamente se ocupan de la administración de justicia en Cataluña. Entre ellas, es preciso contar jueces y magistrados, fiscales, jueces de paz, médicos forenses, secretarios judiciales, funcionarios de distintos cuerpos y personal del Departamento de Justicia dedicado a las tareas de apoyo, sin contar a miles de abogados, procuradores y peritos. Se encuentran repartidos por todo el país: desde los juzgados de paz de pequeños municipios hasta el Tribunal Superior de Justicia de Cataluña, pasando por los juzgados distribuidos en cuarenta y nueve partidos judiciales. Tramitan centenares de miles de incidencias cada año y resuelven centenares de miles de asuntos. Su función es dar solución a conflictos de intereses y de derechos entre particulares, entre los particulares y las administraciones o entre las mismas administraciones. Dejando atrás épocas en que la coacción económica o política podía determinar sus decisiones, hoy la regla general es la del respeto a los principios de imparcialidad e independencia que se presuponen en su conducta.

\section{Una mala reputación}

Sin embargo, la reputación de la administración de justicia -en Cataluña y en toda España- es muy negativa. Figura entre las administraciones e instituciones del país con unas calificaciones más desfavorables. Es un dato alarmante. Cuando la ciudadanía tiene un mal concepto de su administración de justicia -recordemos que la “justicia emana del pueblo" según el artículo 117 de la Constitución-, se debilita la confianza ciudadana en el Estado democrático de derecho que la justicia tiene que garantizar. La cuestión, por tanto, tiene mucha importancia y no puede pasarse por alto. Es obligación de cualquier gobierno procurar que la administración de justicia funcione tan bien como sea posible como pieza capital de todo el edificio democráti- 
co. No es una pieza muy visible y por esta razón no suele ser excesivamente gratificante desde una perspectiva electoralista. Es mucho menos visible, por ejemplo, que el rendimiento de otros servicios e infraestructuras públicas (educación, sanidad, vías de comunicación, etc.) o que los resultados de la actividad económica. Pero todos ellos dependen, en última instancia, del buen funcionamiento de la administración de justicia. Porque es esta administración la que debe asegurar el respeto a los acuerdos y a las normas que protegen los derechos de las personas y de las entidades públicas y privadas.

Debe admitirse también que -desde una visión política partidista- la justicia no suele ser un sector prioritario en las actuaciones gubernamentales. Precisamente por la carencia de visibilidad y de rendimiento electoral inmediato. También por otra razón más profunda: porque algunas de las medidas que sería necesario adoptar para mejorar el servicio de justicia chocan con intereses corporativos potentes, difíciles de contrarrestar. No debe extrañar, por tanto, la cotización relativamente baja que el Ministerio o el Departamento de Justicia suelen tener cuando se trata de distribuir responsabilidades políticas. El resultado es que el servicio público de la justicia no responde a las exigencias de una sociedad avanzada y compleja como es la nuestra, donde se multiplican los conflictos. Si la justicia no recupera el tiempo -mucho tiempo- perdido en su modernización, irá creciendo la distancia entre la demanda social y la respuesta judicial y se intensificará la insatisfacción pública. Un sistema judicial inspirado aun en los patrones del siglo XIX no puede responder adecuadamente a los retos del siglo $\mathrm{XXI}^{5}$. Esta apreciación genérica se me confirmó en el contacto directo con la realidad.

Sigue pendiente, por tanto, una tarea hercúlea y de larga duración. Una tarea tan compleja como la que exige cualquier proceso de modernización de un servicio público, a la cual se oponen rutinas e intereses creados. Pero esta oposición se refuerza en este caso por una condición muy singular de este servicio público: la fragmentación irracional de competencias y de atribuciones entre diversas autoridades. Si es difícil dirigir y aplicar un proceso de reforma en una organización compleja cuando la responsabilidad corresponde a un único centro director, la dificultad se multiplica cuando hay más de un "director de orquesta". En este caso, se superponen el Gobierno del Estado -a través del Ministerio de Justicia-, el Consejo General del Poder Judicial, la Comunidad Autónoma - a través del Departamento de Justicia-, el Tribunal Superior de Justicia o los jueces decanos -con sus atribuciones gubernativas- y los titulares de los órganos judiciales. Sin contar otros actores que influyen sobre el pro-

5 Los esfuerzos para avanzar hacia la modernización de la justicia son antiguos, pero con muy poco éxito. En 1997, el Consejo General del Poder Judicial publicaba un "Libro Blanco", con un buen diagnóstico y propuestas innovadoras que solo han estado muy parcialmente asumidas por los sucesivos gobiernos del Estado. Otro gesto retórico lo significó el discutido "pacto de Estado" sobre la justicia entre el PP y el PSOE, durante la legislatura 2000-2004. Las ambigüedades de este pacto y las vicisitudes de la relación entre los dos grandes partidos estatales dejaron sus acuerdos en vía muerta, salvando una distribución de cuotas de influencia política en la composición del Consejo General del Poder Judicial que tampoco

142 ha servido para pacificarlo. 
ceso, como son los colegios y las asociaciones profesionales y las representaciones sindicales. Los únicos que no tienen intervención directa en la orientación o la gestión de este servicio son precisamente los ciudadanos usuarios. Es decir, aquellos de los cuales la Constitución dice que "emana la justicia”, tal como antes recordaba.

\section{La respuesta de la consejería a las urgencias materiales}

Con este panorama y con competencias restringidas, ¿de qué manera podía orientar la acción del Departamento durante la legislatura que se iniciaba? Era necesario distinguir dos vertientes. De un lado, tocaba cumplir las obligaciones impuestas por el Estatuto y la ley. Pero, por otro lado, también era indispensable promover otras actuaciones en ámbitos que no nos incumbían, pero que presentaban una importancia innegable para la mejora del servicio. Me referiré sucesivamente a las dos facetas.

En lo que respecta a las competencias propias, era obligación urgente del gobierno de la Generalitat renovar las infraestructuras físicas y tecnológicas, que la negligencia o la carencia de priorización de los gobiernos anteriores había dejado en condiciones inaceptables.

- Era urgente auditar todos los edificios judiciales. En muchos partidos judiciales, los juzgados se distribuían aún en edificios dispersos y locales de alquiler compartidos con otros usos. Esta situación -tolerada durante años- no es funcional y es costosa para los trabajadores y usuarios. Pero también para la Generalitat, por los alquileres y por el mantenimiento que debe financiar. El objetivo del plan aprobado fue concentrar en pocos años todos los servicios judiciales de cada partido judicial en un solo edificio propiedad de la Generalitat, hecho que facilitaba el uso racional de las instalaciones y rebajaba los costes de su mantenimiento. El plan inversor prevé la substitución o la mejora de los edificios de veintiocho partidos judiciales sobre un total de cuarenta y nueve. En superficie, estas actuaciones equivalen a más de 250.000 metros cuadrados de obra judicial nueva, sin contar la Ciutat de la Justícia de Barcelona-l'Hospitalet, que ocupa más de 200.000. El importe total del plan inversor -incluyendo la Ciutat de la Justícia- es de más de 520 millones de euros. Este plan representa un esfuerzo presupuestario sin precedentes en la historia de la administración de justicia en Cataluña y, probablemente, en el conjunto del Estado.

- Un proceso similar se siguió con la incorporación de las tecnologías de la información y comunicación al servicio público de la justicia. Se procedió a una valoración de la situación, marcada por la obsolescencia técnica y la carencia de compatibilidad entre equipos y aplicativos. Llamaba mucho la atención que sólo una parte limitadísima del personal tuviera acceso al correo electrónico y a internet o que siguieran en uso sistemas operativos con más de diez 
años de vida. Se procedió a la renovación total de los equipos y a la elaboración de nuevos aplicativos, con programas adecuados. Con esta renovación de la infraestructura tecnológica se hace posible una gestión más eficiente de la justicia. No es condición suficiente, porque hacen falta otras actuaciones más difíciles y complejas que corresponden a otras autoridades. Pero es una condición necesaria para posibilitar la eficiencia y la transparencia que son requeridas a cualquier administración moderna.

\section{Doble hipoteca: una organización obsoleta, una gestión del personal inexistente}

Esta infraestructura física y tecnológica renovada debe ser gestionada por una organización y por un personal determinados. Y es aquí donde empiezan las grandes dificultades de la reforma pendiente del servicio público de justicia. Sobre todo, por la fragmentación de las competencias a la cual ya me he referido. Impulsar un proceso de modernización ambiciosa de la organización y de la gestión del personal ya sería un reto de dificultad extrema si correspondiera a un solo órgano político investido con una autoridad clara. Pero en este caso aparecen una serie de actores que distribuyen atribuciones de manera poco funcional y confusa. Ya lo he indicado antes y deberé volver a ello más adelante. En lo que a la organización se refiere, resultan sorprendentes algunos rasgos de esta administración propios del siglo XIX. Sin entrar en un anecdotario abundante en situaciones -a veces pintorescas y a veces dramáticas-, se pueden reseñar algunas de carácter estructural.

- Se mantiene hasta hoy un funcionamiento estrictamente separado entre órganos judiciales del mismo nivel territorial y entre servicios administrativos de cada uno de ellos, aunque compartan especialización, ámbito territorial de jurisdicción e instalaciones, con el consiguiente derroche de recursos humanos y materiales.

- Se conserva la condición unipersonal de los juzgados de primera instancia e instrucción y se descargan sobre los justiciables los efectos negativos de las vicisitudes personales de su titular único: traslados, sustituciones, licencias, enfermedades, humores, etc. No se tiene en cuenta que, en la mayoría de profesiones cualificadas, el trabajo en equipo o en colaboración es hoy un factor esencial de su eficiencia. La carencia de permanencia estable de los titulares en sus órganos -favorecida por una norma que ignora las conveniencias del servicio público- es una de las causas más importantes de su bajo rendimiento.

- No se ha producido una revisión suficiente del mapa judicial -la técnicamente denominada "planta y demarcación"-, ignorando importantes transformaciones demográficas, económicas o de comunicaciones de nuestra sociedad. Esto hace que hoy coexistan en Cataluña partidos judiciales con menos 144 de 20.000 habitantes y partidos judiciales con más de 200.000, sin contar el 
municipio de Barcelona. Por tanto, en Cataluña hay partidos judiciales que tienen más población -y mucha más litigiosidad- que algunas provincias españolas dotadas de juzgados especializados, de Audiencia Provincial e incluso de un Tribunal Superior de Justicia en el caso de las autonomías uniprovinciales.

- Respecto de los asuntos de que se ocupan, una parte no menor de la tarea de los juzgados de primera instancia e instrucción se dedica a conflictos menores y de carácter repetitivo y rutinario: de esta manera, consumen de forma ineficiente el tiempo y la atención necesarios para cuestiones de más complejidad y de más trascendencia social que también son de su competencia.

Salvando situaciones más favorables en algunas jurisdicciones y órganos, los retrasos generalizados en la resolución y en la ejecución provocan no solamente la incomodidad de los usuarios, sino también costos elevados de carácter social y económico para el conjunto de la sociedad. Este panorama organizativo depende de una legislación estatal centralizadora y uniformista y, a la vez, de una gestión pesada y parsimoniosa del Ministerio de Justicia del Estado. Una gestión que se hace también con una mentalidad uniformista, alejada de las necesidades inmediatas de cada territorio y poco adaptada al ritmo y las necesidades de la sociedad contemporánea.

En lo que al personal se refiere, la situación es igualmente preocupante. Presenta una centralización rígida y poco ágil de su dirección, sin voluntad de poner en marcha fórmulas más adecuadas a la evolución de todas las administraciones contemporáneas.

Como resultado, sólo queda en manos del gobierno de la Generalitat la responsabilidad de gestionar el personal interino que ocupa las plazas vacantes de funcionarios de cuerpos nacionales. Es decir, le corresponde al Govern de la Generalitat atenuar -pero no resolver- los efectos negativos de problemas estructurales graves generados por la centralización injustificada de la gestión del personal funcionario titular a la cual acabo de referirme. Se exige al gobierno autonómico que salga al paso de las deficiencias de la actuación ministerial, pero sin disponer de las atribuciones adecuadas. En términos deportivos, esta extraña gestión de personal podría compararse a la de un equipo en el cual titulares y suplentes se sometieran a entrenadores, entrenamientos y regímenes disciplinarios distintos. Si ya es difícil hacer buen juego con una dirección unificada, podemos imaginar los efectos nocivos de esta dualidad. Por tanto, a pesar de los esfuerzos de la Departamento de Justicia y de una parte del personal afectado, es explicable que nadie quede satisfecho con la situación. Es llamativo, sin embargo, que muchas voces críticas sobre la gestión del personal interino no quieran reconocer las causas de lo que se critica: se concentran solamente en las medidas de emergencia que adopta la Departamento y esconden que estas emergencias son el resultado de una concepción centralista y uniformista que no quieren denunciar por posiciones ideológicas o por intereses corporativos. La paradoja es que muchos de estos críticos -jueces, secretarios y otros funcionarios- son víctimas del mismo sistema que defienden o que de hecho toleran con su conformismo. 


\section{¿Carencia de recursos o carencia de dirección responsable y eficaz?}

Todas estas graves deficiencias tienen su origen en la ausencia de una dirección clara y coordinada sobre el conjunto del personal. Porque ninguna autoridad se encuentra en condiciones o con la voluntad de ejercer esa dirección. Es preciso poner de manifiesto la capacidad y dedicación de un buen número de profesionales del sistema que lo mantienen en funcionamiento a pesar de los defectos crónicos que sufre. Pero también abundan los que se encuentran bastante cómodos en una situación donde predomina la ausencia de control y de rendimiento de cuentas. Y entre los que quisieran ejercer alguna iniciativa de reforma o desearían que alguien la tomara se hallan quienes no pueden hacerlo por carencia de atribuciones legales o por falta de preparación para ello.

Apunté anteriormente que el personal es el activo principal de un servicio público de las características de la administración de justicia. Por esta razón, el elemento más crítico de todo el sistema judicial es una centralización excesiva que no facilita ni una respuesta rápida a las necesidades de cada momento, ni una acción coherente de transformación estructural. Es posible resignarse en este momento a un gobierno centralizado de la judicatura o de la fiscalía, pese a que es discutible su eficiencia: otros países democráticos de estructura federal admiten sin problemas la intervención de las unidades federadas en esta tarea. Pero lo que es totalmente injustificable es la centralización de la gestión del resto de personal técnico y administrativo. No es una posición teórica o ideológica. Se ha demostrado suficientemente -y cada vez con más crudeza- la incapacidad de los sucesivos ministros de Justicia estatales -conservadores y socialistas- para lograr una gestión eficiente de los procesos que afectan a este personal, tanto en Cataluña, como en el conjunto del Estado. Pude comprobarlo en mis relaciones con el Ministerio de Justicia. $Y$ he podido ratificarlo en los contactos con otros consejeros de Justicia de Comunidades Autónomas, que -sin distinción de color partidista- son igualmente conscientes de los efectos negativos de la situación. Porque recae sobre las CCAA la tarea ingrata y poco efectiva de atenuar las graves incoherencias de una gestión ministerial del personal funcionario.

¿Y la escasez de recursos? ¿No estará aquí la causa principal del rendimiento bajo del servicio? "Faltan recursos" es la queja crónica que profieren muchos profesionales de la justicia: jueces, abogados, funcionarios. En algunos casos, de buena fe. En otros, como excusa de su modesta voluntad de trabajo. Al menos en Cataluña, se puede replicar que éste no es el factor principal de funcionamiento deficiente del servicio y de su mala reputación entre los ciudadanos. Ya he reconocido en qué aspectos convenía un esfuerzo para dotar adecuadamente a esta administración: inversiones en parque inmobiliario y tecnología. Pero -a la vista de las cifras comparadas con otros países- no parece que se dé una insuficiente dotación presupuestaria en el gasto corriente ni en el número de órganos judiciales o de efectivos personales. Por tanto, no estamos delante de una cuestión de cantidad. No por volcar más recursos se gana siempre en eficiencia. Al contrario: en las circunstancias actuales, se pueden

146 incrementar las ineficiencias si no se corrigen a fondo las rutinas organizativas y la 
gestión de los efectivos humanos. No se resuelven los problemas de carácter estructural que acabo de describir con la táctica ruinosa de "taparlos con más dinero". No es efectivo. $Y$ además no es responsable por parte de un gobierno que quiera gestionar sus recursos públicos con atención a su utilidad social.

\section{Aprovechando los márgenes disponibles: el Estatuto y las reformas legales}

Ante una situación como la descrita -centralización excesiva, organización obsoleta, ausencia de capacidad directiva, cultura resistente al cambio-, ¿qué margen le quedaba al Departamento de Justicia para actuar, más allá del apoyo material y tecnológico descrito? ¿Debíamos aceptar resignadamente que la solución definitiva no se encontraba en nuestras manos? Pese a las señales poco estimulantes recibidas del propio medio, consideraba necesario adoptar algunas medidas que prepararan el camino de futuras decisiones. Se referían tanto a la normativa y a la gestión administrativa, como a la creación de opinión pública. Subrayaré algunas de ellas y el recorrido logrado.

- El Departamento estaba obligado -por imperativo de una reforma de la Ley Orgánica del Poder Judicial (enero de 2000)- a la preparación de un nuevo modelo de oficina judicial y a su implantación en Cataluña. El margen de definición que la ley permitía no era menospreciable a pesar del carácter uniformista de la norma estatal. El Departamento -por obra de la dirección general competente- aplicó mucha dedicación a la preparación de esta reforma, con la intención de ponerla en marcha. Mi sentimiento sobre esta reforma era ambivalente. De un lado, compartía la creencia de que se trataba de una renovación necesaria para resolver algunas deficiencias seculares del sistema. De otro, experimentaba una reserva escéptica acerca de la posibilidad de aplicarla con resultado positivo. ¿Por qué razón? Porque es muy difícil imaginar que la autoridad responsable de esta transformación -sobre el papel, el gobierno de la Generalitat- pueda superar las resistencias muy fuertes al cambio mientras que no tenga plena capacidad plena para dirigir al personal que tiene que aplicarlo. Pese a ello, el Departamento -y la dirección general en particular- dejó fijada la definición de la nueva estructura de la oficina y de sus servicios, pendiente ahora de una operación de complejidad notable y que puede suscitar una receptividad muy desigual -adhesión, pasividad, hostilidad, boicot- entre sus futuros actores y beneficiarios.

- Mirando hacia el futuro, el nuevo Estatuto debía ser también una gran oportunidad para reactivar la modernización inaplazable de este servicio. De acuerdo con el Institut d'Estudis Autonòmics, el Departamento intervino en los trabajos preparatorios. En su redacción final, el nuevo Estatuto podía ayudar a superar las carencias principales de la administración de justicia. No se trataba de satisfacer apetencias soberanistas: se trataba, sobre todo, de facilitar la modernización de un servicio público que todo el mundo admite que 
no funciona como debiera. Para modernizarlo, el Estatuto incorporaba tres criterios fundamentales: desconcentración del gobierno de la judicatura, descentralización de la gestión del resto de personal y aproximación de la jurisdicción al territorio y a la sociedad. A pesar de lo que se ha afirmado desde la derecha política y desde la derecha judicial -que un magistrado veterano me calificó irónicamente de expresión redundante-, ninguna de estas propuestas atenta contra la unidad o la independencia del poder judicial, ni es incompatible con ellas. Sí es incompatible, en cambio, con la resistencia a aceptar los defectos reales de la justicia y someterlos a su tratamiento efectivo. Una resistencia que proviene de fuertes prejuicios ideológicos, de potentes intereses corporativos y de notables incapacidades de visión estratégica ${ }^{6}$.

- El Estatuto de 2006 incorpora, pues, un potencial de reforma a pesar de su remisión a una futura legislación estatal que por imperativo constitucional debe concretar muchas previsiones estatutarias. Con conciencia de este condicionante legal, el Departamento trabajó paralelamente en la confección de propuestas de enmienda de la legislación estatal para adaptarla a las previsiones del nuevo Estatuto y no frustrar las expectativas abiertas. Se trata de evitar la triste historia de las previsiones del Estatuto de 1979, abortadas después por una centralista Ley Orgánica del Poder Judicial de 1985 y sus sucesivas modificaciones. Encargué este trabajo preventivo a un grupo de juristas expertos. Informé al Ministerio de este trabajo de adecuación normativa entre el futuro Estatuto y la reforma pendiente de la Ley Orgánica del Poder Judicial. Con un temor extremo a los poderes fácticos del sistema judicial, la actitud del Ministerio era conservadora y defensiva: la más adecuada para perder cualquier batalla reformista que se quisiera plantear con objetivos de modernización. Después de diversas reuniones bilaterales con el equipo ministerial -alguna bastante pintoresca y agotadora por la exuberancia retórica de mi interlocutor principal-, llegué a la conclusión de haber entrado en una vía muerta. Era menester, pues, trabajar de otro modo y procurar la complicidad de otras CCAA que sufrían los mismos problemas que Cataluña y que recibían del Ministerio el mismo trato. Con esta intención, establecí contactos con las consejerías de Andalucía, Galicia y el País Vasco. Esta estrategia resultó algo más productiva, tal como indico más adelante.

\section{Provocar el debate social: el Libro Verde de la Administración de Justicia}

En todo caso, cualquier reforma estatutaria o legislativa no será nunca suficientemente efectiva si no se produce también otro tipo de cambio. Un cambio

6 Las referencias al Estatuto catalán de 2006 que aparecen aquí y en otras partes de este texto fueron redactadas antes de que el Tribunal Constitucional dictara su tan esperada sentencia (STC 31/2010). Se impuso en ella una visión poco o nada favorable a explotar un margen de interpretación constitucional que permitiera una renovación a fondo en la administración de justicia (cfr. supra, nota 2). 
que tiene que afectar a la opinión pública y, de rebote, a los mismos profesionales de la justicia. La sociedad -articulada en agentes sociales y económicos, entidades profesionales y culturales, medios de comunicación- responde a los defectos de la justicia con una doble reacción. Se escandaliza estentóreamente ante algunos episodios llamativos de su bajo rendimiento. Pero, como norma general, adopta un fatalismo sufrido: se ha acostumbrado al funcionamiento deficiente de este servicio público, se ha resignado a considerarlo incorregible y se ha convencido de que cualquier iniciativa reformadora comporta riesgos para quien lo promueva.

Por esta razón, me parecía necesario exponer con claridad y franqueza ante la opinión pública y en distintos escenarios la situación real de la justicia, cuáles eran las líneas de transformación que era necesario impulsar y de qué recursos se debía disponer. Además de las comparecencias parlamentarias, los actos y entrevistas institucionales propias del consejero y de muchas conversaciones personales, no rechacé la oportunidad de manifestarlo sistemáticamente ante auditorios que me parecían adecuados para debatir la cuestión. No sé con qué grado de impacto sobre el escepticismo dominante, intenté estimular una contribución social más activa -en forma de reclamación pero también de impulso y de consejo- a la modernización de este servicio público. Si la opinión de estos actores sociales se expresa a menudo para reclamar mejores infraestructuras y servicios -aeropuertos, autopistas, investigación, educación, seguridad, etc.- ¿por qué no pedir su movilización en pro de la modernización de un servicio del cual depende en última instancia la calidad de otras intervenciones públicas?

Con este objetivo, propuse la confección de un Libro Verde sobre la Administración de Justicia en Cataluña. El punto de partida debía ser la recogida de información actualizada sobre la situación de la justicia en el país. Esta recogida de información era por sí misma una contribución valiosa para la elaboración de las políticas de intervención. Un trabajo arduo del Gabinete Técnico del Departamento, supervisado por la Comisión Permanente del Consejo de Justicia, generó y ordenó documentación abundante, hasta entonces no localizable o disgregada. Es suficientemente conocido que las resistencias al cambio se amparan a menudo en la ocultación o la ignorancia de los datos relevantes. Por esto era y es tan importante mantener al día información cuidadosa.

Del debate general sobre los datos recogidos en el Libro Verde resultaron un centenar de recomendaciones. La gran mayoría fue aprobada por unanimidad. Unas pocas - una docena- lo fueron por mayoría muy amplia, con la oposición de algunos representantes de la judicatura y del personal funcionario. Las recomendaciones iban dirigidas a todas las administraciones responsables en la materia, con la intención de hacer un seguimiento periódico del grado de cumplimiento. Porque sin una hoja de ruta y sin una evaluación sistemática del progreso realizado no será posible avanzar de manera significativa por un camino que todo el mundo sabe que está lleno de obstáculos y trampas. 


\section{La regla de proximidad}

No hay fórmulas mágicas para obtener esta transformación general del servicio público de la justicia. Pero si se me pidiera una recomendación sintética, la condensaría en una sola regla: más proximidad. Aproximar la prestación del servicio a sus destinatarios procuraría un doble beneficio: reforzaría la legitimidad y aumentaría su eficiencia. Esta aproximación es necesaria y conveniente en muchas dimensiones de la justicia como organización, como servicio y como poder?.

- Una primera aplicación de la regla tiene que situar las decisiones jurisdiccionales en instancias más cercanas al ciudadano. A este objetivo responde una doble medida: la atribución del Tribunal Superior de Justicia del recurso de casación y la definición de una justicia local en algunos núcleos urbanos. Son previsiones incorporadas en el Estatuto de 2006 que deberían de tener su traducción en las reformas de la Ley Orgánica del Poder Judicial y otras leyes procesales de las que ya he hablado. Disminuir distancias jurisdiccionales debería abreviar procesos y evitar dilaciones excesivas, sin perjudicar la calidad y el rigor del servicio prestado. En lo que se refiere a las funciones del Tribunal Superior de Justicia de Cataluña -y a los de otras CCAA-, hace unos años era general y compartida la posición favorable a dotar a este Tribunal de una capacidad jurisdiccional efectiva que ya previó la Constitución de 1978. Lo afirmaban magistrados y académicos. Pero en los últimos años ha sido perceptible una reacción conservadora que insiste en mantener la posición dominante del Tribunal Supremo, alertando sobre presuntos problemas que generaría la existencia de diecisiete Tribunales Superiores de Justicia como últimas instancias territoriales. Lo que había sido considerado útil desde una perspectiva rigurosamente técnica ahora aparece -en plena ofensiva política recentralizadora- como un riesgo de fragmentación del Poder Judicial. La manipulación política del debate pone en peligro la aplicación futura de esta herramienta necesaria para modernizar el sistema judicial español.

Una polémica similar se ha generado alrededor de la propuesta de constituir juzgados de proximidad en algunos centros urbanos. Se trata de una propuesta antigua, nacida en la ciudad de Barcelona para hacer frente a los conflictos menores o a conductas transgresoras que conviene sancionar con celeridad -y con garantías- en beneficio de la convivencia social. La resistencia a esta fórmula relativamente innovadora -que cuenta con precedentes en otros países- proviene de la defensa de intereses corporativos y se disfraza a menudo con inconvenientes técnicos.

7 No ha sido ésta la orientación que se impuso en la Sentencia 31/2010 al optar por una versión rigurosa y discutible de la unidad del poder judicial, poco adecuada para adaptarlo a las necesidades de la sociedad actual. Las expectativas que mi texto contenía sobre dicha adaptación y que se exponen en los párrafos siguientes parecen ahora poco viables mientras perdure aquella visión. 
- Una segunda dimensión de la proximidad es de carácter instrumental y afecta a la gestión de jueces y otros funcionarios. Es instrumental pero no secundaria, porque se refiere al personal, activo principal de este servicio público. En el caso de la magistratura, el Consejo General del Poder Judicial debe desconcentrar sus atribuciones en beneficio de órganos territoriales, como el Consejo de Justicia previsto también en el Estatuto de 2006. Esta desconcentración es perfectamente compatible con un cuerpo judicial único de ámbito estatal. No se fractura esta condición y tampoco se vacía la atribución última del Consejo General para gestionarlo. Pero aproxima la capacidad de decisión al territorio donde se producen las incidencias que deben resolverse, con un conocimiento más directo de las urgencias, las prioridades y las circunstancias que lo rodean. Para los demás funcionarios, todas las atribuciones que siguen en manos del Ministerio deberían transferirse a las CCAA, sin perjuicio de los derechos de movilidad estatal y de previsión social de los profesionales. Las objeciones corporativas y políticas suscitadas por esta propuesta no resisten un análisis hecho desde las conveniencias de una buena organización del servicio público. La fórmula incorporada del Estatuto de 2006 facilita la aproximación necesaria de la gestión de este colectivo a las autoridades del territorio donde presta sus servicios. La considero una de las condiciones necesarias -probablemente la más influyente- para una auténtica renovación del servicio y de sus resultados, porque depende de ella la viabilidad de otras reformas.

- Finalmente -pero no de menor importancia- la tercera dimensión de la proximidad se debe concretar en una mayor inteligibilidad del ritual y del lenguaje judiciales. No es admisible que estos rituales, procesos y lenguajes continúen siendo poco asequibles para el ciudadano, cuando la voluntad ciudadana es la fuente de la que emana la legitimidad de la justicia democrática. A la necesaria eliminación o simplificación de tramitaciones y fórmulas arcaicas, oscuras y redundantes que perviven en el mundo jurisdiccional, es preciso añadir de manera imprescindible la plena normalización del catalán como lengua de la justicia. La posición residual que actualmente ocupa el catalán en la justicia no concuerda con la que ocupa en la vida social y administrativa del país. Ni tampoco con la legislación lingüística vigente. Presuntos derechos de los funcionarios no pueden ir en detrimento de los derechos constitucionales de los ciudadanos a los cuales deben servir como empleados públicos. Son necesarias medidas de apoyo y de incentivo, a las cuales se deben añadir también disposiciones legales y cambios culturales. $Y$ no solamente entre los funcionarios al servicio de la administración de justicia. También y quizá de manera principal entre abogados y procuradores del país, reticentes aún al uso normal del catalán ante los tribunales. Puede ser comodidad. O por comodidad disfrazada de temor poco justificado a una reacción desfavorable de las instancias judiciales.

La proximidad como regla debería repercutir en una mayor eficiencia del servicio público de la justicia. A todos los que no admiten que la justicia sea un servicio y su- 
brayan el carácter de Poder estatal, es preciso recordarles que un servicio eficiente es el que da más legitimidad y credibilidad a la justicia como Poder democrático y, con ella, al Estado democrático como tal. No hay, pues, contradicción entre su doble condición de servicio y de Poder, siempre que se acepte que se trata de un poder democrático. Aceptación de la que hacen dudar algunas afirmaciones y conductas -por suerte minoritarias, pero muy escandalosas y persistentes- de algunos miembros de la profesión.

\section{Jueces, fiscales, funcionarios, abogados, ministros y otros interlocutores}

Las políticas judiciales -su definición, su aplicación- son responsabilidad de los gobiernos del Estado y de la Generalitat en la medida de sus competencias respectivas. Pero deben contar -como todas las políticas públicas-con otros actores implicados en su ejecución. No son ni pueden ser actores neutros, ni sumisos: defienden convicciones e intereses que en ocasiones coinciden y en otras ocasiones se contraponen con las convicciones de quien tiene la responsabilidad democrática de gobernar y de defender el interés general. He mantenido durante tres años un contacto frecuente con estos interlocutores. Haré un repaso telegráfico -y, por tanto, con pocos matices- de las impresiones que he obtenido de estos contactos. Es un ejercicio arriesgado que debe ir precedido de un aviso: las apreciaciones genéricas sobre un colectivo no son igualmente extensibles a cada uno de sus miembros.

- Con el personal judicial, los órganos de los cuales es titular y las asociaciones que le representan, las relaciones han estado presididas en general-siempre hay alguna excepción- por la cortesía propia de quien tiene responsabilidades institucionales. Es de agradecer cuando esta cortesía empieza a ser infrecuente en otros ámbitos. Pero han estado marcadas también por otras connotaciones $y$, en especial, por la posición mayoritariamente conservadora del colectivo cuando se trata de avanzar por el camino de la innovación. Demasiado a menudo la innovación se percibe como una amenaza -incomodidad, riesgo, complicación- más que como una oportunidad para la mejora. En el comportamiento hacia el gobierno de la Generalitat, subsiste la reticencia a considerarlo como actor político corresponsable del servicio, y se le reduce a menudo a la condición subordinada de instrumento administrativo de carácter auxiliar. En lugar de hacer una valoración estratégica de las actuaciones que es preciso adoptar, las reacciones del colectivo judicial y de sus órganos de gobierno suelen concentrarse -con las excepciones honorables propias de toda regla- en la reivindicación constante y casi "sindical" de más recursos, sin demasiada -o ninguna- autocrítica documentada de su propio rendimiento y dedicación. El resultado es una relación poco constructiva y un diálogo desequilibrado: los representantes de la judicatura parecen tener derecho a exigir rendimientos a la administración de la Generalitat, pero la administración de la Generalitat -a pesar de su carácter de representante de la ciudadanía- no puede atreverse a pedir rendimientos y resultados a la judica- 
tura y a sus órganos. Esto se concreta en una reacción básicamente "incrementalista" de la magistratura ante los problemas que padece. Una reacción que también tiene su raíz en la cultura individualista de la profesión y en su escasa preparación para encuadrar las urgencias inmediatas en una perspectiva estratégica más general. Al mismo tiempo, cuando en algún caso he identificado actitudes sinceras de carácter reformador dentro del mismo colectivo judicial, ha sido poco frecuente verlas expresadas de manera pública y contundente por los mismos que las pronunciaban en privado.

- En la fiscalía, además de la cortesía institucional, he detectado una disposición más favorable a una colaboración institucional en pro de la mejora del servicio gracias a las personalidades que la han representado en Cataluña en los últimos años. Pero también debido a la misma naturaleza de la institución, estructurada de manera jerárquica, con responsables que la dirigen con una visión de conjunto. $Y$, por tanto, con más conocimiento y experiencia de lo que es la gestión y la organización de los recursos humanos que la componen. A pesar de sufrir -a veces más que la judicatura- los inconvenientes de una estructura mal diseñada y poco dotada y del impacto de reformas procesales adoptadas sin previsión ni recursos, la fiscalía no solía instalarse en la queja crónica. Demostraba mayor capacidad para contribuir a la búsqueda de salidas posibilistas -cuando era la única vía transitable- o de aportar sugerencias de innovaciones de fondo -cuando existía la probabilidad de ponerlas en marcha-. En síntesis, una visión al mismo tiempo más realista y más a largo plazo que la registrada en otros colectivos del sector.

- Los secretarios judiciales aparecen sobre el papel como una pieza central en la marcha de los órganos judiciales. Desde el Departamento así lo entendimos. Pero se detecta en el colectivo una crisis de identidad profesional. A veces, se presentan como participantes en la actividad propiamente jurisdiccional, en paralelo o como complemento del papel del juez. A veces, se postulan como garantes insustituibles de la regularidad de los procedimientos, a pesar de que el apoyo tecnológico actual hace menos decisiva esta intervención de lo que lo era poco tiempo atrás. Una muestra elemental de este cambio de rol es, por ejemplo, la grabación obligatoria de las vistas orales. Con menos frecuencia, se consideran responsables de la gestión de la oficina judicial y de su personal, pero en general manifiestan poca disposición para ejercerla. Esta indefinición de funciones la resuelven los buenos profesionales con dedicación y preferencias personales por una u otra de las tareas descritas, supliendo a menudo las carencias de otros actores -jueces, funcionarios, interinos- del órgano judicial en que prestan sus servicios. Por el contrario, esta indefinición de perfil es para otros profesionales un pretexto para un bajo rendimiento del cual no responden ante nadie: ni ante la judicatura a la que asisten, ni ante el Ministerio de quien dependen sobre el papel, ni ante la Generalitat que no tiene la competencia legal. La creación de una Secretaría de gobierno en cada Tribunal Superior de Justicia y de Secretarías 
coordinadas en las Audiencias Provinciales podría ser un primer paso para establecer una estructura de responsabilidades más ordenada y más clara. Pero si esta estructura y su personal permanecen vinculados al Ministerio de Justicia y no son transferidos a las CCAA, será difícil obtener de esta figura una contribución más efectiva a la mejora del servicio público.

- El personal administrativo al servicio de los órganos judiciales -los denominados "cuerpos nacionales" de especialización y niveles distintos- exhibe características similares a los otros cuerpos burocráticos. Pero, a diferencia de los que actúan en los servicios públicos de educación, sanidad u otros, este colectivo profesional no ha sido transferido a las CCAA. Esta anomalía perjudica el buen rendimiento del servicio, pero también el reconocimiento y la promoción de los buenos profesionales. A pesar de su papel residual en la organización del servicio, la administración autonómica es un interlocutor obligado con la representación sindical de estos trabajadores. Una representación sindical que quiere obtener las condiciones laborales y salariales del personal de la Generalitat, pero sin asumir las mismas obligaciones, alegando su condición de personal estatal no transferido. Una ecuación imposible de resolver, a pesar del tiempo y la energía que el Departamento aplica a gestionar esta situación incongruente. Pese a todo, la consejería cerró un acuerdo plurianual con las representaciones sindicales, intercambiando algunas mejoras salariales con mejoras en la distribución horaria de sus dedicaciones en beneficio del servicio. Un intercambio insuficiente para llegar a condiciones realmente satisfactorias para la profesionalidad de los trabajadores y para el ciudadano destinatario del servicio. Porque, mientras no se materialicen las previsiones del Estatuto de 2006 y no se transfieran a las CCAA este personal se mantendrá en una terra nullius, que imposibilita una clara dirección y un efectivo rendimiento de cuentas. Algunos miembros dedicados de este personal y su moral profesional son las víctimas principales de este mal diseño, mientras otros obtienen un buen partido para su confort particular. Con un impacto final muy desfavorable para el servicio público.

- Interlocutor obligado de la Departamento es el Ministerio de Justicia. La normativa constitucional y estatutaria deja en manos del Gobierno del Estado importantes competencias que afectan la administración de justicia en Cataluña y en todas las CCAA. De los contactos con el Ministerio, extraje dos conclusiones desfavorables para una posible mejora de la justicia. La primera es que la interpretación ministerial de las actuales competencias reconocidas a las CCAA es sustancialmente restrictiva. La segunda es que la disposición a ampliar estas competencias autonómicas en beneficio del servicio es sumamente débil. Lo producen la tradición centralista y el instinto de conservación de una burocracia ministerial que quiere justificar su propia existencia y la del personal judicial que ocupa posiciones directivas o consultivas en el propio Ministerio. Esto explica que la oferta de concertación ordenada entre las dos administraciones -la estatal y la catalana- que planteé al ministro 
López Aguilar no tuviera una acogida efectiva. A pesar de nuestro origen universitario común y de una simpatía personal inicial, las largas conversaciones pusieron de manifiesto, no solamente estilos verbales bastante contrastados sino también la diferencia de planteamientos políticos. Fue prácticamente imposible avanzar en el aprovechamiento de las posibilidades del momento y en la exploración de posibilidades futuras. Durante tres años, no sirvió de gran cosa la coincidencia entre el color político del Gobierno de Rodríguez Zapatero y la orientación del Govern de Maragall: han podido más la resistencia burocrática y la incapacidad resolutiva de los políticos ministeriales.

- Las CCAA con competencias en justicia han sido también interlocutores de la Departamento durante estos tres años. No son todas las Comunidades del Estado, porque -a pesar de los esfuerzos del Ministerio por transferir este servicio- las CCAA se resisten a aceptarlo. Y es explicable. Son conscientes de la descapitalización en que se encuentra este servicio y de la dificultad de gestionarlo mientras no se modifique la actual distribución de competencias: en una palabra, no pueden hacerse cargo de lo que no tendrán capacidad para arreglar. Respecto de las CCAA que ya las han recibido, he comprobado que coinciden en el diagnóstico de los problemas pendientes, con independencia del color político del gobierno autonómico y aunque varíen la prioridad y la determinación que dediquen a su resolución. Esta coincidencia de posiciones permitió incorporar a las reformas estatutarias de otras CCAA unas previsiones casi idénticas a las contenidas en el texto catalán de 2006. También permitió trasladar al Ministerio de manera concertada las mismas demandas. Esta iniciativa causó sorpresa -y una cierta irritación- en el Ministerio al comprobar que las consejerías socialistas de Andalucía y de Galicia las únicas en manos del PSOE en aquel momento- compartían las posiciones del Departamento del "sospechoso" Govern tripartito de Cataluña. Las reuniones de la Conferencia sectorial de consejeros de Justicia -que el Ministerio intentaba convertir en un simple trámite administrativo- se convirtieron en algún momento en el escenario de debates tensos e intensos de carácter estratégico. Esta aproximación entre CCAA podría ser uno de los mecanismos para forzar un tratamiento menos centralista y más eficiente del servicio público, haciendo retroceder progresivamente los obstáculos políticos y corporativos que se le oponen. Conviene señalar que, a pesar del color político distinto de los distintos gobiernos autonómicos, las CCAA competentes en justicia suscribieron (septiembre de 2006) un documento sobre reformas y transferencias de competencias que concordaba con las posiciones previstas en el Estatuto catalán de 2006.

- En la esfera profesional, abogados y procuradores son cooperadores indispensables de la administración de justicia y de la función de garantía de los derechos de los ciudadanos. En cierto modo, comparten la responsabilidad de sus virtudes y de sus defectos. El colectivo de procuradores debe esforzarse -y procura hacerlo- por reconvertir su función tradicional y demostrar 
que su presencia aporta valor añadido al sistema de justicia. En sus relaciones con la consejería, ha predominado el sentido institucional y la cooperación respetuosa y leal por intentar resolver problemas y prever conjuntamente reformas positivas.

- Los colegios de abogados, por su lado, agrupan un contingente extremadamente numeroso y muy heterogéneo de profesionales. Su crecimiento en las últimas décadas ha sido desmesurado y desproporcionado en comparación con la mayoría de países de nuestro entorno. Aunque a veces se vea relegado a un segundo plano, este exceso de oferta profesional es una de las causas principales de algunos de los problemas de la administración de justicia. Dentro de este gran colectivo, coexisten estatutos laborales y sociales muy diversos y, en algunos casos, bastante precarios e inestables. Todos estos factores provocan preocupaciones y tensiones internas que tienen un encaje difícil en la estructura tradicional de los colegios de abogados. Para algunos, el colegio debería seguir siendo la instancia de encuentro entre profesionales liberales que comparten normas de conducta y garantías de un cierto rigor técnico. Para otros, debería convertirse en instrumento de defensa casi sindical de los intereses de unos trabajadores jurídicos, asalariados o pseudoautónomos. Finalmente, hay quien -por razón de su estabilidad profesional- puede ignorar a la institución colegial y en la práctica prescinde totalmente de la misma. He conocido ejemplos de todas las clases. Y he comprobado las dificultades crecientes -y probablemente insolubles- de los representantes colegiales de la profesión para responder de manera coherente a las condiciones y exigencias a menudo contradictorias de sus representados.

Un caso sintomático de esta inconsistente reacción corporativa -explicable por la situación socioprofesional que he descrito, pero injustificable desde la perspectiva del interés general- lo proporcionó la respuesta de los colegios a una iniciativa del Departamento sobre la prestación del servicio público de asistencia jurídica gratuita, más conocido por la denominación inadecuada de "turno de oficio". Es preciso aclarar para los que lo ignoran que la asistencia jurídica gratuita se financia con dinero público, mediante el presupuesto del Departamento de Justicia. Según analistas y profesionales, este servicio arrastra desde hace años problemas importantes de calidad, transparencia y gestión. Pero el crecimiento de la demanda del servicio, producida por reformas legales y por nuevos fenómenos sociales -violencia de género, inmigración, delincuencia juvenil-, obligaba desde hacía tiempo a una revisión de su eficiencia en calidad y gestión. La dotación presupuestaria prevista para este servicio equivalía en el año 2006 a un veinte por ciento del presupuesto del personal del Departamento dedicado a la administración de justicia: es decir, una quinta parte de este gasto era gestionado externamente por los colegios profesionales. Es una magnitud considerable. Por esta razón, es democráticamente exigible que los que prestan el servicio -de otro lado, profesionales voluntarios y no obligados- y los que lo 156 gestionan -los colegios como entidades de derecho público- acrediten una utiliza- 
ción eficiente y de calidad de los recursos aportados por el contribuyente en beneficio de los sectores sociales más frágiles.

Un análisis encargado a un grupo de abogados en ejercicio independientes y externos al Departamento provocó reacciones airadas de algunos sectores de la profesión que consideraban amenazados sus intereses, poniendo en circulación interpretaciones falsas sobre el contenido del documento ${ }^{8}$. El final de la legislatura -octubre de 2006- interrumpió el proceso iniciado. Las presiones ejercitadas por los colegios sobre algunos representantes de partidos políticos -tanto del Govern como de la oposición- generaron el reflejo conservador que los aparatos partidistas experimentan a menudo ante los intereses organizados, especialmente en periodos preelectorales y aunque sea a costa del interés general. Se puede afirmar, pues, que el inmovilismo ganó este primero round. Pero la cuestión sigue abierta y la realidad de las cosas obligará -como ha sucedido en otros países- a encararla con decisión.

\section{Conclusión provisional: un pronóstico poco optimista}

No es un descubrimiento el mal estado de la administración de justicia y las grandes dificultades que existen para mejorarla. La situación altamente ineficiente de este servicio público perjudica el progreso económico y social del país. Y, por lo tanto, afecta de manera particular a los sectores más vulnerables de la sociedad. Son los que tienen menos capacidad para organizarse y expresarse y para recurrir a mecanismos alternativos de protección de sus derechos. Por esta razón, un gobierno de progreso y cambio debería situar la reforma de la justicia entre sus objetivos prioritarios. Pero estas intenciones reformadoras en beneficio del interés general chocan con colectivos organizados con potencia singular: la fuerza que les da su incrustación en el seno de los aparatos estatales y su dominio de los instrumentos jurídicos, que es el lenguaje instrumental propio de la misma institución estatal. Son, pues, operadores de la misma organización que debe ser reformada y son creadores y usuarios de la herramienta con la que se debe realizar la reforma. Esta condición explica la potencia de las inercias conservadoras que predominan en dichos sectores. Sólo pueden ser compensadas con la movilización de otras energías sociales y con otras herramientas: la transparencia informativa, la evaluación de los resultados, la aproximación y la participación de otras instancias ciudadanas, el contraste con experiencias positivas de otros países.

No es suficiente la implicación de los profesionales directamente vinculados a la justicia: jueces, fiscales, abogados, personal de apoyo. Su intervención es indispensable, pero no puede ser exclusiva ni dominante. Como en otros sectores de la burocra-

8 El documento fue publicado también en la web del Departamento. Sus autores -cuatro abogados de reconocida experiencia- hacían una valoración de la situación de la asistencia jurídica gratuita en Cataluña y examinaban algunas alternativas a su organización, a partir de experiencias de otros países que también habían revisado el servicio tras constatar las carencias. 
cia y de otros mundos profesionales, las resistencias al cambio continúan siendo más potentes que los proyectos de renovación. Y las voluntades políticas suelen ser demasiado frágiles cuando deben acometer tareas difíciles y de dudoso rendimiento electoral. Por todo ello, sin la participación de otros sectores que deseen esta modernización porque perciben su necesidad, la administración de justicia no llegará a ser un servicio razonablemente bien organizado, bien gestionado, eficiente y, finalmente, bien valorado por la opinión pública.

Después de tres años de contacto con esta cuestión, he de confesar que -a pesar el irrenunciable optimismo de la voluntad que debe profesar todo progresista homologado- me resulta difícil esquivar el pesimismo de la razón cuando se me pregunta por el pronóstico futuro de la justicia: en Cataluña y en España. La coalición de intereses inmovilistas supera a día de hoy las fuerzas de una posible coalición social de modernizadores. Se requerirá mucha energía -especialmente de los actores sociales- para reforzar los impulsos fragmentarios de cambio e intentar combinarlos en el seno de un proyecto coherente.

\section{LA POLÍTICA PENITENCIARIA: UNA POLÍTICA SOCIAL EN MARCHA}

Actualmente, Cataluña -y España entera- se sitúan a la cabeza de los países europeos en cuanto a magnitud de su población penitenciaria. Este crecimiento acelerado en pocos años no es resultado de un aumento significativo de la delincuencia. Todas las estadísticas corroboran esta paradoja: infracciones penales relativamente estabilizadas, pero incremento incesante de la población sometida a sanciones. La explicación inmediata de esta aceleración es un endurecimiento de la legislación penal y de su interpretación. Es la respuesta política -simplista e ineficaz- a un clima social de incertidumbres e inseguridades múltiples. Una respuesta que nunca acaba de tranquilizar suficientemente a una opinión pública demasiado ignorante sobre la realidad del mundo penitenciario. Por esta razón, al hacerme cargo de la cuestión, me pareció necesario trabajar en dos frentes. Por un lado, era urgente construir las bases de un servicio penitenciario eficiente. Por otro, era indispensable aplicarse a un ejercicio constante de pedagogía, explicando que una política penitenciaria solamente puede tener ciertos niveles de éxito si se relaciona con las políticas orientadas a disminuir las situaciones de marginación existentes en una sociedad. Es decir, si la política penitenciaria se contempla como una política social y se sitúa efectivamente en este ámbito. De no ser así, el fracaso del servicio público penitenciario es seguro. Esta es la convicción con la que emprendimos las actuaciones que comento a continuación.

\section{Contradicciones de la opinión pública y debilidades de los gobiernos}

El castigo penitenciario adquiere cada vez mayor extensión y más relevancia cuando la sociedad experimenta incertidumbres e inseguridades de todo tipo. Pero

158 este recurso a la sanción penal suscita reacciones contradictorias. Se ensalza como 
garantía imprescindible de la tranquilidad de los ciudadanos y, al mismo tiempo, se rechaza como realidad incómoda y molesta. Se reclama más acción penitenciaria, pero se la quiere situada lejos de nuestra vida y de nuestra imaginación. Y, al mismo tiempo, algunos rasgos superficiales que identificaban tradicionalmente al mundo penitenciario -vestuario, tatuajes, argot, estética personal, etc.- son adoptados como una moda, transgresora pero perfectamente comercializable por las grandes marcas. Lo que predomina -más allá de los tópicos- es una ignorancia general sobre la realidad penitenciaria, a la que se exige mucho y a la que se valora poco.

Así ha sucedido también en Cataluña, la única Comunidad Autónoma española con competencias ejecutivas en la materia. Una posición singular que atravesó dos fases. En una primera etapa, las transferencias del servicio - del personal y de las instalaciones- a la Generalitat permitió la corrección de los principales defectos de la situación recibida. Defectos muy graves que reclamaban una reacción inmediata. Pero esta primera etapa dio paso a una gestión continuista, con poco empuje para profundizar en la renovación del sistema y para prevenir con suficiente tiempo las necesidades futuras. El resultado de esta doble incapacidad era ya visible al final de la década de los noventa. Instalaciones muy congestionadas y obsoletas, malestar de un personal sin horizonte profesional, tácticas informativas defensivas por parte de la administración: estos eran los rasgos de la situación penitenciaria vista desde la oposición. A esta degradación contribuyeron de manera singular una política estatal de rigor penal exagerado. Esta política del "penalismo salvaje" era producto de la deriva conservadora de los últimos años de gobierno del Partido Popular (PP), que -con el apoyo del Partido Socialista Obrero Español (PSOE)- había endurecido determinadas previsiones del código penal. No a causa de un aumento significativo de la delincuencia que las estadísticas no detectaban, sino como respuesta fácil a sectores de la opinión que convierten sus incertidumbres y miedos de cualquier tipo en exigencias de represión de otros.

El problema es que esta respuesta fácil acaba siendo contraproducente. El recurso a las penas de cárcel -y a largas penas de privativas de libertad- para sancionar determinadas conductas antisociales fomenta a menudo la predisposición de muchos infractores a mantenerse en la marginalidad social. Desde mi punto de vista, es erróneo confiar a la cárcel la resolución de determinados problemas de nuestra sociedad. Pero es doblemente erróneo adoptar esta posición represiva sin dotar a la política penitenciaria de los medios y los recursos adecuados. El dato es que en España -y en otros países - se incrementa la presión represiva, pero se descuida la política penitenciaria. Los efectos inmediatos del mal planteamiento son el incremento acelerado de la población penada, la sobreocupación de los centros penitenciarios y la insuficiencia de personal preparado para gestionar un servicio que se oriente a la reeducación y reinserción del delincuente, tal como exigen la Constitución y la Ley General Penitenciaria.

Estas contradicciones desembocan en percepciones negativas sobre la política penitenciaria. No es atractiva para los políticos porque se considera un "marrón" -se- 
gún el argot del propio medio-, sin oportunidad de lucimiento político y con mucho riesgo. A la imagen negativa se le sumaba, en nuestro caso, la evidencia de las dificultades graves que sufría el sistema. Por esta razón recibí muchas expresiones de pésame -sincero o ficticio- cuando asumí esta responsabilidad. Desde la perspectiva con que había entrado en la política institucional, en cambio, no me parecía una responsabilidad gubernamental más dura que otras si se quiere dar respuesta a necesidades urgentes que tiene el país: degradación de la educación, desbarajuste urbanístico, deterioro medioambiental, crecimiento de las desigualdades sociales, modernización de la administración, etc. La receta para afrontar cualquiera de estos retos no es demasiado distinta: ideas claras y contrastadas de lo que debe hacerse a medio y largo plazo, un buen equipo de colaboradores, recursos económicos suficientes y disposición a una carrera de largo recorrido que no se puede abandonar a cada tropiezo o a cada protesta interesada. Convenía aplicar, pues, estos criterios a la política penitenciaria. Con conciencia, además, de que en un mundo bastante cerrado -y no es ironía- como es el mundo penitenciario existen junto a las normas escritas pautas no escritas de conducta que no es posible ignorar.

\section{Romper el aislamiento y la opacidad: "socializar" el sistema penitenciario}

Las características y el momento de la política penitenciaria requerían explicar su situación con mucha transparencia, con todos sus claroscuros. Se produce la paradoja de que algunos rasgos de la vida de las cárceles excitan mucho la curiosidad de los medios de comunicación. Se trata generalmente de los episodios y aspectos más negativos, asociados al fracaso del mismo sistema y de sus principales protagonistas. Una fuga o un caso de indisciplina interna -más o menos grave- pueden acaparar fácilmente mucho espacio y tiempo en los medios. Pero esta fascinación por su lado oscuro es compatible con la ignorancia amplia de sus características generales, de sus objetivos o de sus éxitos. Que también los hay.

Una de las causas de esta visión parcial y deformada proviene de la actitud de algunos profesionales del mundo penitenciario y de sus responsables políticos. Comparten a menudo una posición defensiva ante los medios y la opinión, tal vez originada en una inseguridad sobre la justificación de su propio trabajo. Me parecía imprescindible revisar el modo de tratar públicamente la cuestión penitenciaria. Convenía, en cierto modo, "socializar" el asunto. Es decir, compartir oportunidades y dificultades que presenta con toda la sociedad y sus representantes cualificados, tanto en el momento de definir y explicar los problemas, como en el momento de elaborar soluciones. Sin esta "socialización", la administración penitenciaria en solitario no dispondría de fuerza suficiente para abandonar rutinas defensivas e incapaces de dar una respuesta apropiada a sus necesidades.

A la vez pensaba también en otra "socialización" de la política penitenciaria. Me refiero a la necesidad de situarla claramente como otra más entre las políticas socia-

160 les de todo gobierno progresista. Centrarse de manera casi exclusiva en la vertiente 
represiva o de seguridad -que también la tiene- de esta política es intentar atacar a los síntomas de un mal sin tratar sus causas. El derecho penal y la cárcel deben ser el último recurso de una comunidad para tratar los fracasos de sus miembros y el fracaso de la misma comunidad. Pero no son adecuados para erradicar sus causas. Si la comunidad no tiene conciencia de esta diferencia, se genera una espiral insostenible: más incremento de población penitenciaria y más incremento de la delincuencia se alimentan recíprocamente. Los Estados Unidos son un buen ejemplo de ello.

Al llegar al Departamento, uno de nuestros primeros documentos de trabajo fue sometido a la consideración de un equipo externo al cual me dirigí para validar o corregir las grandes líneas estratégicas de una nueva política penitenciaria. Tuve la fortuna de conquistar la complicidad entusiasta de una serie de personas que aportaron a esta tarea una alta sensibilidad social, una larga experiencia política y profesional y una visión libre de las urgencias electorales. Cabe decir que este primer paso tuvo mucha influencia en el proceso posterior: por su contenido y por su significación. Se confirmó mi convicción y la del equipo del Departamento acerca de la necesidad de contar con este contrapunto social en el momento de tomar decisiones difíciles o de proponerlas al Govern. Pienso que esta aproximación no partidista a los problemas graves del país facilita la definición de sus soluciones. Sin dimitir de la responsabilidad que le corresponde a todo gobierno democrático, la consulta con otros actores políticos y sociales incrementa la legitimidad del curso adoptado y protege al gobierno de las tentaciones de abandonar frívolamente este curso cuando le parece que el viento electoral le es desfavorable.

\section{Ordenar y renovar un sistema penitenciario nacional}

Ante todo, debía quedar claro ante la opinión pública que el sistema penitenciario catalán sufría desde hacía tiempo dos carencias graves: carencia de instalaciones funcionales y ausencia de dirección adecuada en la política de personal.

Empiezo por la cuestión de la renovación de las instalaciones penitenciarias y de los problemas provocados por su implantación territorial. Pocos días después de mi toma de posesión, estallaba un primer conflicto territorial acerca de esta cuestión. Sin indicación de la fuente, saltaba a la prensa que el anterior gobierno de CiU había adquirido unos terrenos en la comarca del Bages, con la intención de instalar un nuevo centro penitenciario. Ni el ayuntamiento del municipio afectado, ni tampoco yo en calidad de nuevo consejero habíamos recibido información por parte del gobierno saliente. La noticia provocó una fuerte reacción local de oposición al proyecto. El procedimiento del gobierno de CiU era desacertado y claramente desleal hacia las autoridades locales. Además de la marginación del gobierno del municipio, algunos detalles de las transacciones patrimoniales sobre la finca elegida levantaron sospechas de especulación y tráfico de influencias, provocando dimisiones en algunos organismos comarcales y algunas actuaciones ante la justicia que finalmente no prosperaron. 
Este cúmulo de circunstancias hacía explicable una reacción adversa como la producida. Pero esta resistencia ciudadana a la implantación de un centro penitenciario revelaba también las contradicciones de una opinión pública mal informada. Como ya he dicho, la tendencia equivocada a reclamar más penas de cárcel para garantizar más seguridad pública a menudo se manifiesta simultáneamente con el rechazo a la instalación penitenciaria necesaria para ejecutar esas penas. Es un ejemplo de manual de la reacción colectiva que la ciencia política conoce como reacción nimby. En los últimos doce años, no se había abierto en Cataluña ningún nuevo centro penitenciario a pesar de la creciente presión de las cifras. Para esquivar reacciones populares negativas, el gobierno anterior había concentrado una ampliación insuficiente en los mismos municipios donde existían ya otros centros penitenciarios, con escasa funcionalidad para el conjunto del sistema.

El episodio del Bages confirmaba una vez más que sólo un tratamiento sistemático podía esquivar las dificultades inevitables de este aspecto de la política penitenciaria. Un tratamiento global debía contener la definición de los modelos de centro penitenciario, el esquema básico para su distribución sobre el territorio y una actitud de concertación con los gobiernos locales, acompañada de incentivos para beneficiar el entorno social y territorial del equipamiento. Se trataba de dibujar y construir un sistema nacional de centros penitenciarios, en lugar de ir a remolque de las circunstancias y diseminar estas instalaciones sin ningún criterio director. Todo ello requería un fuerte compromiso político y presupuestario del Govern. Finalmente, era preciso abandonar el secretismo que caracterizó actuaciones anteriores en la materia. Un secretismo que nutría aún más la percepción pública de que se trataba de una materia inconveniente y peligrosa.

Renovando planteamientos de fondo y forma, presenté al Govern un proyecto de decreto para incentivar de manera objetiva y pública a los gobiernos locales que estuvieran dispuestos a alojar una instalación penitenciaria. Con ello quería evitar un regateo vergonzante entre el gobierno de la Generalitat y los municipios, como se había producido por parte del gobierno del CiU con resultados poco objetivos. Igualmente, presenté al Govern un Plan de Equipamientos Penitenciarios 2004-2010. La capacidad del sistema alcanzaría aproximadamente unas once mil plazas en condiciones adecuadas. El coste estimado de la inversión superaba los setecientos millones de euros. El Govern hizo suyas estas propuestas, con plena conciencia de que se trataba de una política nacional -y social, como he destacado antes- que era preciso desplegar con firmeza y a medio plazo. No se trataba de una política especialmente vistosa ni electoralmente rentable. Pero era absolutamente imprescindible para el interés general. Y, al mismo tiempo, necesaria si se quiere legitimar la reivindicación de la plena capacidad de autogobierno, una reivindicación que pierde justificación si se esquivan aquellas competencias más difíciles de asumir y desplegar de manera efectiva.

Con este cuadro de referencia y con el apoyo del Govern, el Departamento fue 162 superando las incidencias inevitables del recorrido para encontrar los emplazamien- 
tos de cada nuevo centro y definir los proyectos correspondientes. A pesar de las protestas y las movilizaciones opositoras, en algo más de un año se determinó la ubicación de cinco de los nuevos centros previstos. De manera miope y desleal, los partidos de la oposición intentaron manipular estos movimientos de resistencia a la solución de un problema que los mismos partidos -CiU con el apoyo del PP- no habían resuelto en diez años de gobierno. La reserva o la oposición expresadas por algunos miembros locales del PSC y ERC -que también existieron- no tuvieron el apoyo de sus direcciones nacionales, comprometidas con la propuesta del Govern tripartito.

¿Cómo se pudo llegar a este conjunto de decisiones sobre las implantaciones penitenciarias que muchos consideraban inalcanzables? ¿Por qué se salvaron los obstáculos reales que los gobiernos anteriores de CiU no habían logrado superar? Corresponde a otros hacer una evaluación más objetiva. Pero quiero avanzar algunos de los rasgos que favorecieron el resultado final:

- La presentación del plan general que entiende el sistema penitenciario como un sistema nacional, y no como una serie de instalaciones esparcidas aleatoriamente por el territorio.

- La comunicación permanente con la representación municipal de los posibles emplazamientos, sin maniobrar a sus espaldas con tácticas desleales.

- La persistente explicación -de carácter pedagógico- a la opinión pública acerca de la necesidad urgente de estas infraestructuras, su carácter no agresivo y los beneficios que se derivan para el entorno.

- Finalmente -pero no menos importante- fue de gran ayuda la cooperación de algunos alcaldes y consistorios. Demostraron tener una visión de país y, al mismo tiempo, se comportaron como negociadores exigentes pero constructivos, en defensa de los intereses de sus localidades cuando se trataba de definir las condiciones de acuerdo entre su ayuntamiento y el gobierno de la Generalitat. También colaboraron muy positivamente alcaldes de poblaciones que ya contaban con la experiencia de alojar centros penitenciarios, demostrando la ausencia de efectos negativos y el impacto favorable sobre el entorno. Una vez más, se puso de manifiesto la necesidad ineludible de esta colaboración permanente entre los gobiernos locales y el gobierno de la Generalitat para resolver los problemas del país.

De todo ello resultó un cambio de actitud en algunos sectores cualificados de la opinión. E incluso de algunos medios de comunicación inicialmente más inclinados a privilegiar las expresiones estridentes de la oposición a las instalaciones penitenciarias. Creo que se consiguió gradualmente el reconocimiento público de la necesidad social de estas instalaciones como condición para una política penitenciaria propia de una sociedad avanzada. 


\section{Tan urgente como importante: definir y aplicar una política de personal}

La otra gran cuestión pendiente del sistema penitenciario catalán era la dirección y gestión del personal. Prestaban este servicio cerca de tres mil personas, con una cultura profesional bastante singular. A pesar de la dedicación de muchos de ellos, el colectivo sufría graves carencias. Un número muy elevado de interinos, un método muy deficiente de selección, formación y promoción, una autoridad precaria por parte de sus directivos, una falta de consideración social: esta suma negativa era producto de la ausencia de una estrategia a medio plazo. A diferencia del personal de la administración de justicia, en este caso no existía la excusa de una falta de competencias de la Generalitat. Porque las competencias habían sido transferidas aunque no se habían desarrollado de manera eficiente. En este entorno, se había ido imponiendo cierta autorregulación ejercida en buena medida por las instancias sindicales, lo cual permitía “ir tirando" pero no satisfacer las auténticas necesidades del servicio. Mal punto de partida para abordar el crecimiento incesante del número de internos y las lamentables condiciones de las instalaciones.

Entre el personal penitenciario, era posible identificar un sector vocacionalmente entregado a su difícil tarea, un contingente adaptado a las inercias dominantes y una parte cómodamente instalada en un régimen laboral que le permitía de hecho otras ocupaciones. Era injusto y poco eficiente descargar el peso de un servicio público tan exigente en los profesionales auténticamente motivados por su oficio. Por tanto, era preciso escuchar las opiniones y disponer de la cooperación de este primer grupo, marcar líneas claras y objetivos precisos al segundo grupo y procurar la marginación progresiva del último.

Mientras preparábamos las primeras medidas para enderezar esta situación, se produjo un incidente muy grave en el centro penitenciario de Quatre Camins. Un grupo de internos agredió con gran violencia al subdirector y retuvo durante unas horas a otros funcionarios. A pesar de la gravedad de los hechos, la pericia de algunos profesionales penitenciarios hizo innecesaria la intervención de los mossos d'esquadra que los Departamentos de Interior y Justicia habíamos preparado. Pero la confusión del momento permitió la irrupción en el centro de un número importante de personal penitenciario no autorizado, una parte del cual planteó un pulso a la dirección del centro, al secretario de servicios penitenciarios y al mismo consejero. Manifesté allí mismo que en aquellas graves condiciones y bajo la amenaza de un plante me parecía políticamente inadmisible y éticamente injustificable la formulación de aquellas exigencias. Se dejó claro que en aquellas circunstancias no podía darse una negociación. Solamente restablecida la normalidad del servicio, la negociación se situaría en el lugar y el momento adecuados.

Para el consejero y para el secretario de Instituciones Penitenciarias, aquellas horas de una madrugada de abril constituyeron un útil "bautismo de fuego" para la 164 larga serie de negociaciones posteriores con las representaciones sindicales acos- 
tumbradas a determinadas prácticas de presión y a singulares métodos de agresividad verbal y literaria. Esa noche se puso de manifiesto que ni el Departamento, ni las representaciones sindicales cederíamos fácilmente ante las respectivas pretensiones. Repetí a menudo que no estaba dispuesto a perjudicar la prestación del servicio penitenciario a cambio de una cómoda "paz sindical”. Pero dije también -consciente de las gravísimas carencias del sistema- que nos esforzaríamos por corregirlas con la colaboración del personal que tuviera vocación real de servicio público. Para mí, era una condición esencial no confundir los papeles de cada uno de los actores que la dejadez del periodo anterior había enturbiado. La política penitenciaria -también en materia de personal- debía ser definida por el Departamento después de dialogar con la representación sindical, para someterla a la aprobación del Govern. La ejecución de esta política correspondía a los directivos profesionales del sistema penitenciario y de cada centro. A la representación sindical le correspondía expresar y defender los intereses de los trabajadores, pero no le tocaba definir la política penitenciaria ni convertirse en su intérprete principal.

Esta toma de posición fue recibida inicialmente con gran hostilidad por parte de la representación sindical, con actuaciones que parecían querer poner a prueba la voluntad de reforma del consejero. Después de esta clara manifestación de intenciones, se inició un proceso largo y complejo de negociación en el cual debían combinarse el cumplimiento de compromisos concretos de un nuevo acuerdo marco adaptado a las necesidades de la política penitenciaria que se iniciaba. Es decir, un acuerdo que encajara con la política de personal definida por el Departamento y no una política definida solamente por el acuerdo sindical. Costó llegar a él, porque era necesario superar desconfianzas iniciales, malas prácticas de épocas pasadas y también obstáculos derivados de la ya comentada falta de política de personal en el conjunto de la Generalitat. Finalmente, se firmó un acuerdo plurianual 2006-2009 con las tres principales organizaciones de los trabajadores penitenciarios (abril de 2006), en un clima de respeto mutuo, imprevisible en los primeros contactos. Probablemente todos habíamos aprendido alguna cosa durante todo el proceso que nos había hecho coincidir en algunos puntos necesarios para la mejora del servicio.

En particular, y además de la constancia y la habilidad de los negociadores de la Secretaría, ayudó también la claridad de los planteamientos de conjunto defendidos por la Departamento, junto con la credibilidad adquirida con las decisiones difíciles sobre el plan de inversiones penitenciarias. Pienso que quedó clara la existencia de una visión muy precisa sobre lo que debía de ser el sistema penitenciario catalán y de la voluntad decidida para llevarla a cabo sin someterla a la incertidumbre de circunstancias o de incidentes de recorrido. Así se manifestó claramente en todas las actuaciones y en todas las comunicaciones dirigidas a la opinión pública y al propio personal penitenciario.

¿Cuáles eran los objetivos principales de esta política de personal? Puedo señalar los siguientes: 
- La reducción de una elevada interinidad, que -además de ser injusta para los trabajadores- es siempre un factor de disfunciones importantes en el rendimiento del servicio y en su calidad.

- El refuerzo de la autoridad directiva en los centros, modificando su estructura y también el estatuto de los directores en beneficio de una mayor desconcentración funcional.

- El incremento gradual del conjunto de la plantilla, de acuerdo con el crecimiento de centros y del número de internos.

- La definición de nuevos sistemas de selección, formación y promoción en la carrera profesional, más ajustados a las exigencias del servicio y a las capacidades del personal.

- La revisión de los sistemas de asignación de turnos y horarios para optimizar la calidad en la prestación del servicio.

- La incorporación del personal con funciones sanitarias y docentes a los colectivos correspondientes de la administración autonómica.

En tres años, se dieron los primeros pasos para avanzar de manera razonable en la ejecución de las medidas necesarias. La aplicación de estas medidas se debía escalonar hasta 2009. El resultado debería ser un personal adaptado -en número, formación y dedicación- al sistema penitenciario de una sociedad avanzada, orientado por los objetivos constitucionales de la reeducación y la reinserción de los internos. En síntesis, un personal penitenciario cada vez más seguro de su calidad profesional y de su consideración social, con la plena confianza y la valoración positiva de la ciudadanía.

Para lograrlo, era preciso contar con la colaboración de las organizaciones sindicales del sector público. Esto requería evitar algunas malas prácticas existentes en las relaciones entre las representaciones sindicales de los trabajadores públicos y los gobiernos. En estas relaciones, los gobiernos no siempre demuestran el esfuerzo, la convicción y la capacidad de innovación necesarias para evitar que los acuerdos suscritos con el personal no acaben perjudicando al interés general. Con demasiada frecuencia, las presiones de los sindicatos y las concesiones de los gobiernos de turno quieren ganar la "paz social y electoral" a cualquier precio. De este modo se perjudica la calidad del servicio y se dan argumentos potentes a los partidarios de la privatización progresiva de todos los servicios públicos. Nuestra intención fue, en todo momento, evitar este riesgo en beneficio de un servicio público penitenciario gestionado por personal competente y socialmente reconocido.

\section{Más atención individual al interno}

He insistido en la acción del Departamento en materia de infraestructuras y ges166 tión del personal. Son las condiciones indispensables para contar con un servicio de 
ejecución penal que cumpla de manera efectiva con lo que establece la Constitución y la Ley General Penitenciaria, una de las más avanzadas de nuestro entorno. Pero estas reformas ganan sentido si cuentan con el impulso político de un gobierno que se proponga luchar contra todas las formas de exclusión social. La delincuencia tiene a menudo su origen en esta exclusión, como elemento principal o como elemento coadyuvante. Por desgracia, la sanción penal que sigue a la conducta delictiva puede ser -y de hecho lo es a menudo- una causa añadida de segregación social, situación que refuerza la situación original de marginación. Por esta razón he señalado ya que el esfuerzo del Departamento pretendía situar a la política de ejecución penal entre las políticas sociales del Govern de Maragall. Este cambio de acento significaba -entre otras cosas- aplicar más recursos cualificados al tratamiento individualizado de los internos, con más atención a la diversidad de tipologías delictivas y a la circunstancia personal de cada uno de ellos. Representaba igualmente ampliar la oferta de trabajo remunerado a los internos, uno de los instrumentos más útiles para su reinserción. Finalmente, comportaba más apoyo a la ejecución de medidas penales alternativas que en todas partes se manifiestan más eficientes para la rehabilitación de la mayoría de los delincuentes.

Para hacerlo posible, se procedió a revisar y reforzar una serie de instrumentos:

- Se potenció la colaboración con los gobiernos locales y entidades de cooperación social para la ejecución de medidas penales alternativas a la prisión que han ido aumentando de manera muy notable. Se reforzaron los equipos destinados al control y seguimiento de la ejecución de estas medidas. Se inició la definición de un proyecto de agencia autónoma especializada que pudiera gestionar más eficazmente la ejecución de dichas medidas.

- Se ha constituyó una comisión de cooperación institucional entre todas las administraciones -denominada CIRSO- que, con carácter desconcentrado en todo el territorio, tiene como objeto poner en común los recursos que todas las administraciones -educativa, sanitaria, local, cultural, de vivienda, etc.- pueden aplicar a la reinserción social de los delincuentes.

- Con la creación de una Mesa de Participación Social (marzo de 2004) como órgano consultivo de la administración penitenciaria, se potencia y se ordenan las relaciones con las entidades sociales y del voluntariado que colaboran con el sistema penitenciario. La integran entidades -educativas, religiosas, deportivas, culturales, etc.- dedicadas a tareas muy diversas de asistencia a los internos. Pero, además de su trabajo asistencial, estas entidades son factores muy efectivos para la "socialización" de la actividad penitenciaria a la cual me he referido: se convierten en canal de comunicación permanente con el entorno social para hacerle llegar una imagen más fiel de una realidad poco conocida.

- Finalmente se relanzó la actividad de la empresa pública CIRE -Centre d'Iniciatives per a la Reinserció-, después de una profunda reorganización y 
con un reforzado apoyo por parte del Departamento. Corresponde a esta empresa la promoción del trabajo retribuido para los internos. También le corresponde la gestión de su formación ocupacional, de acuerdo con los programas públicos. Los resultados obtenidos en poco tiempo son una buena prueba de lo que es posible lograr con una estrategia bien definida y un equipo motivado. Ha crecido el número de internos con trabajos remunerados que ha llegado casi al cincuenta por ciento de los que son aptos para ello - y se han mejorado sus condiciones laborales, se han diversificado las actividades y las fuentes de ocupación y se han establecido relaciones estables con asociaciones empresariales y sindicales, con las obras sociales de las cajas y con otras organizaciones, asociándoles a una actividad fundamental para la reeducación de la población reclusa. Con una gestión profesional y eficiente, el CIRE ha podido alcanzar objetivos sociales hasta ahora no logrados, mejorando a su vez sus resultados económicos. Creo que puede considerarse una “historia de éxito" en el sector público.

Estas y otras actuaciones han contribuido -y tendrán que contribuir más a medio plazo- a cambiar el foco de la ejecución penal. Un foco que debe concentrarse más en el tratamiento individual de los internos y que no debe tener en la reclusión el mecanismo principal de sanción, porque existen instrumentos más eficientes en resultados y socialmente más integradores que la cárcel. El potencial de estos instrumentos debe explotarse más a fondo. A pesar del esfuerzo de estos tres años, la urgencia por mejorar las condiciones básicas de todo sistema -personal e infraestructuras- no ha permitido alcanzar todo lo que sería preciso conseguir. Por esta razón conviene ahora reforzar la mejora de los procesos de tratamiento penitenciario y las medidas penales alternativas en beneficio de la comunidad. Deben ser la sustancia de la ejecución penal en una democracia, donde la reeducación y la rehabilitación -y no la venganza- constituyen la justificación del castigo.

\section{La información como obligación democrática y como herramienta de apoyo}

¿Cuántos presos se han fugado este mes? Ésta es la pregunta -simpática o sarcástica- que se dirige a menudo a los responsables de la gestión penitenciaria. En cambio, es inimaginable otro tipo de pregunta. Por ejemplo: ¿cuántos presos habéis rehabilitado este año? La primera pregunta responde a la idea simplista de que la función penitenciaria es mantener encerrados a los delincuentes condenados. Y nada más. La segunda pregunta reflejaría la visión constitucional de la cárcel -y de la ejecución penal en general- como servicio público destinado a conseguir que la población penada no vuelva a delinquir. Esta diferencia de enfoques es sustantiva. Y en ocasiones ni la propia administración judicial o penitenciaria la tienen claramente asumida. Ello explica que dichas administraciones sean capaces de dar respuesta al primer interrogante, porque conservan los datos pertinentes. Pero, en cambio, no disponen de los datos para contestar a la segunda cuestión. Ello se debe a que contabilizan las

168 situaciones de reincidencia o de incumplimiento de las sanciones. Por el contrario, no 
reúnen datos sobre el número -no escaso- de personas que dejan de delinquir después de haber cumplido penas por su conducta antisocial.

Disponemos, pues, de la estadística del fracaso. Pero no contamos con la estadística del éxito. Pésima situación para hacer marketing de este servicio de cara al exterior. Y también situación indeseable para reforzar la autoestima y la moral de todos los que trabajan y colaboran en el sector, porque a menudo no pueden comprobar el efecto positivo real de su actividad. Pese a ello, me pareció imprescindible dar a conocer de manera regular las estadísticas del mundo penitenciario catalán, con un conjunto de indicadores cuantitativos sobre la situación y su evolución. Esta difusión tenía como objetivos:

- Rendir cuentas, como debe hacer toda la administración, ante el ciudadano que financia los servicios públicos.

- Ampliar el conocimiento sobre la actividad penitenciaria para lograr más implicación ciudadana en esta política social.

— “Normalizar” la exposición del mundo penitenciario a la opinión pública, corrigiendo inercias de poca transparencia y de ocultación, a menudo por falta de convicción en su función social.

- Finalmente, situar las incidencias negativas del servicio en un contexto donde existen también episodios positivos.

Todo el mundo debe saber, por ejemplo, cuál es la evolución de la población penitenciaria y el ritmo de crecimiento o disminución que experimenta. Todo el mundo ha de estar en condiciones de conocer cuál es el coste diario por cada interno que asume el presupuesto público, una cifra que sorprende generalmente por su elevada cuantía. O el número de internos que siguen tratamientos especializados según los delitos cometidos, que reciben educación reglada o que trabajan con retribución. Todo el mundo debe conocer el número de salidas y permisos -miles cada año- que conceden los jueces o la administración penitenciaria. Y también debe conocer el grado de cumplimiento por parte de los internos de las normas que regulan estos permisos. Solamente de este modo se pondrán en contexto los casos de vulneración de estas normas: es decir, de los no retornos o de las evasiones. Sólo con un conocimiento suficientemente preciso del mundo penitenciario es posible disipar tópicos, prejuicios y desinformaciones que dificultan la buena gestión del servicio y su legitimación ante la ciudadanía que lo financia y, por tanto, tiene que controlarlo.

Pero no se trata solamente de facilitar estadísticas. También es necesario promover el contacto directo con la realidad penitenciaria. Por este motivo, tiene que ser un objetivo del Departamento y de la Secretaría facilitar el acceso a los equipamientos penitenciarios a diversos representantes sociales, económicos y políticos del país. A través de los medios y con visitas personales a los centros, sin ocultar las defi- 
ciencias del sistema, pero huyendo del sensacionalismo truculento que un imaginario literario y cinematográfico excita entre algunos observadores. Ha sido una experiencia gratificante comprobar cómo este contacto directo -acompañado de la divulgación de datos objetivos- ha podido modificar el carácter negativo que domina la percepción sobre el mundo penitenciario, sus problemas y sus límites. Se disipan fantasmas y reticencias. Se borran prejuicios y simplificaciones. Se despiertan impulsos personales e institucionales para ayudar a las personas que se encuentran en situación de reclusión. A la vista de estos resultados, creo en la utilidad de mantener y regularizar un programa permanente de visitas a los centros penitenciarios, a fin de "normalizar" su percepción como servicios públicos de interés general.

\section{La justicia juvenil: más difícil todavía}

Muchos de los rasgos de la situación penitenciaria catalana son compartidos por su sistema de justicia juvenil, dedicado a la sanción y a la reeducación de los delincuentes menores de edad. No se había preparado una respuesta al impacto producido por la entrada en vigor de la nueva ley estatal de responsabilidad penal del menor (Ley Orgánica 5/2000, de 12 de enero). Este bloqueo tuvo efectos más negativos porque coincidía con una evolución profunda de la delincuencia juvenil: aumentaba en cantidad, se modificaba el perfil de sus protagonistas -conductas más agresivas, diversidad de orígenes nacionales y culturales-y, por lo tanto se hacía más compleja la tarea de su corrección.

\section{Una sociedad demasiado permisiva con las agresiones a los jóvenes}

Las dificultades de la justicia juvenil son grandes y crecientes, en Cataluña y en todos los países de nuestro entorno. No dejaré de señalar una vez más -como he hecho a menudo durante estos años tanto en público como en privado- que no puede cargar sobre el sistema de justicia juvenil -por eficiente que pudiera ser- la responsabilidad de resolver un problema social de raíces profundas y de repercusión dilatada. La sociedad -se afirma- es hoy demasiado permisiva. Ciertamente. Pero esta permisividad no es solamente la que se practica respecto de algunas conductas de sus jóvenes y adolescentes. La permisividad social de consecuencias más dramáticas y nocivas es la que beneficia a los autores de agresiones permanentes que reciben cada día los mismos niños, adolescentes y jóvenes, convertidos en víctimas fáciles de una gran ofensiva comercial. Una agresión potente que manipula todo tipo de recursos emocionales porque se ejecuta constantemente de manera avasalladora con el auxilio de todos los medios de comunicación y ocio. El objetivo de esta agresión es alimentar -especialmente, entre la juventud, como colectivo más vulnerable- unas necesidades inagotables de consumos de todo tipo y excitarles a la satisfacción inmediata, sin consideración por las consecuencias que esta dinámica tiene sobre el mismo sujeto, sobre sus relaciones personales y sobre la socie-

170 dad en general. 
Esta ofensiva se despliega con un bombardeo publicitario sin tregua, por la vía directa -las campañas expresas- o indirecta -la fabricación de ídolos populares de referencia, ensalzados por la admiración y la imitación de la población infantil y juvenil-. Estos modelos de referencia, estos estereotipos a emular, están omnipresentes en el gran sistema mercantil de ocio juvenil (música, moda, cine, videojuegos, videoclips, televisión, internet, etc.), a menudo vinculado también al comercio de drogas legales e ilegales. Este complejo "lúdicomercantil" es equiparable al complejo industrial militar denunciado en otras épocas y mueve también grandes cantidades de dinero. Es el que determina hoy los valores y reglas de conducta de gran parte de los jóvenes. No estoy afirmando que este complejo lúdico-consumista sea determinante en todas las conductas delictivas de los jóvenes. Pero sí creo que las favorece de manera muy potente en el caso de personas que no cuentan con la protección suficiente que suministra un contexto estructurado en lo que se refiere a familia, barrio, escuela o trabajo.

No puede sorprendernos, por tanto, que vaya creciendo el número de jóvenes que cuestionan o que vulneran directamente las normas de comportamiento necesarias para preservar un grado indispensable de convivencia social: desde las infracciones menores que alteran la tranquilidad ciudadana o que infringen las reglas de tráfico motorizado hasta las formas de agresión violenta entre ellos o a terceros, incluyendo a padres y familiares. Merece reflexión el hecho que el porcentaje de jóvenes infractores respecto de su grupo de edad es hoy superior al porcentaje de adultos infractores respecto del suyo. En el año 2006, el número de jóvenes catalanes de catorce a veintiún años sometidos a medidas penales o de reeducación juvenil equivalía aproximadamente a un 3,5 por mil del grupo de edad correspondiente. La proporción de adultos de veintidós a setenta años sometidos a medidas penales equivalía a aproximadamente a un 2,5 por mil de su grupo. Existen, pues, más infracciones entre los jóvenes que entre los adultos, sin considerar la gravedad de los hechos sancionados. Es un dato que conviene tener en cuenta cuando se trata de orientar las políticas sociales más adecuadas.

En este contexto, ¿qué se le exige al sistema de justicia juvenil? Se le pide que intervenga como último recurso para resolver un problema originado en una larga cadena de episodios negativos anteriores. Este último recurso a la sanción judicial puede funcionar en determinados casos y contando con determinadas condiciones. Pero desde la justicia juvenil- no podrá hacerse el milagro de transformar el clima social donde se crean las condiciones generadoras de aquellas conductas delictivas. Debe aceptarse igualmente que ni la escuela, ni la familia, ni ninguna otra institución -social, cultural o religiosa- son capaces de compensar por si solas los efectos de aquella campaña masiva que se perpetra veinticuatro horas al día. Sin una alianza positiva que las vincule, estas instituciones no podrán compensar la potencia del adversario. También en este aspecto los medios de la justicia juvenil deben colaborar en tareas preventivas.

Con todo, tres años de intervención me han hecho ver que no será suficiente una coalición positiva entre actores sociales y actores institucionales si no se tienen muy 
presentes las causas últimas del fenómeno. No basta tratar la cuestión de la delincuencia de los menores en términos de orden público o de reeducación juvenil. Sigue pendiente una tarea de gran vuelo político, orientada a desactivar en origen la agresión institucionalizada contra los jóvenes que significan determinadas praxis económicas. Los agresores levantan la bandera de la libertad de empresa o de la libertad de expresión para justificar sus excesos. Por esta misma razón, es preciso armarse para una batalla política e ideológica que enfrenta modelos de sociedad. Me parece urgente poner de manifiesto el contraste que hay entre dos opciones de fondo, poco conciliables. De un lado, la encubierta opción social propugnada por las industrias legales e ilegales que fomentan conductas incompatibles con valores de responsabilidad individual y de solidaridad social. De otro lado, la opción que ve en estos valores la garantía de cohesión social indispensable en una comunidad civilizada. Quien quiera contar con un sistema de justicia juvenil eficiente también deberá posicionares en esta gran batalla política y social de fondo y en todas las escaramuzas cotidianas que la expresan.

\section{Balance positivo con pronóstico moderadamente esperanzado}

Con todas las dificultades referidas, tres años dedicados a la política penitenciaria y de justicia juvenil me han dejado un buen sabor de boca. Puede parecer extraño, teniendo en cuenta la percepción que la opinión y la misma clase política mantienen sobre este sector. Pero he podido entrever la posibilidad real de transformar positivamente el servicio penitenciario, a medio plazo y a partir de algunas condiciones esenciales. La Generalitat dispone de competencias lo suficientemente amplias en materia de personal y de organización. A diferencia de la situación en administración de justicia que ya he comentado, la responsabilidad prácticamente exclusiva de la cuestión penitenciaria recae sobre el ejecutivo catalán. También son igualmente claras las responsabilidades de la Generalitat en materia de inversiones: corresponde a su gobierno marcar el ritmo y la intensidad del esfuerzo inversor. Y existe también un margen normativo autonómico: la aprobación de un nuevo reglamento penitenciario catalán -pendiente desde hacía décadas- incorpora a partir de ahora posibilidades organizativas y de tratamiento más aptas para las finalidades legales y constitucionales del servicio.

La condición principal para mejorar el sistema penitenciario es la voluntad política de un gobierno que ve en la ejecución penal y la reeducación juvenil una pieza de sus políticas sociales. Y que, en consecuencia, las dota y gestiona como corresponde a una prioridad política del mismo. Este fue el caso del Govern de Maragall, que demostró aquí que era un gobierno nacional y de izquierdas. Es decir, interesado en ejercer de la mejor manera posible su espacio de autogobierno y a hacerlo con una clara orientación social. A pesar de las limitaciones del periodo y de los recursos, me parece innegable que ha empezado una nueva etapa en la acción penitenciaria de la Generalitat: en personal, en tratamiento, en instalaciones, en consideración ante la opinión pública.

Creo, pues, que la Generalitat tiene a su alcance las condiciones positivas para 172 una recuperación de la política penitenciaria y de justicia juvenil. Pero este pronóstico 
no puede ignorar una amenaza grave: la oleada de hiperpenalismo salvaje con el que se pretenden ocultar los miedos e incertidumbres de la sociedad de hoy. Con el derecho penal se quiere hacer frente a sensaciones de inseguridad individual y colectiva que no se corresponden directamente con la delincuencia: precariedad laboral, incremento de la agresividad y de la competitividad económica, riesgo de desprotección social, insatisfacción consumista, indefinición de identidades personales y familiares, enfermedades globales, degradación ambiental, terrorismo, etc. Es fácil manipular los miedos y las emociones más primarias, pero es muy peligroso -además de inútilintentar apaciguarlas con herramientas de represión penal que conducen a limitaciones de derechos ciudadanos y a la inseguridad jurídica.

Ésta es la trampa en la que caen también los gobiernos y las mayorías progresistas cuando impulsan o apoyan esta regresión preocupante del derecho penal contemporáneo. Y éste es el riesgo que pesa sobre una posible mejora de nuestro sistema penitenciario. El temor a oponerse a un estado de opinión generado por manipulaciones mediáticas -que a menudo tampoco se basan en datos significativos- paraliza en algunos políticos la capacidad de tomar decisiones favorables al interés general. Mala forma de hacer política.

Para finalizar este balance, Ilamo la atención sobre el hecho paradójico de que me haya correspondido poner en marcha la construcción de más instalaciones penitenciarias que a ninguno de mis predecesores a pesar de mi convicción declarada de que el internamiento en prisión no es -salvo en casos específicos- la mejor fórmula de sanción penal. Para mí, construir más cárceles no expresa más confianza en este instrumento. Pero también he manifestado la convicción de que cárceles en mejores condiciones -juntamente con otras medidas y actuaciones- son instrumentos de buena práctica penitenciaria. No podemos permitirnos que se confirme en Cataluña la cruel afirmación de un experto: "Una prisión mal gestionada es el método más caro y más eficaz para incrementar la delincuencia de un país".

Las valoraciones globales que hago sobre esta etapa de política penitenciaria me llevan a un balance razonablemente positivo respecto de las actuaciones emprendidas. Me inspiran un pronóstico moderadamente esperanzado sobre su futuro, siempre que se mantengan las líneas adoptadas, con las correcciones necesarias de toda obra política en marcha. Se atribuye a Churchill la afirmación de que el grado de civilización de una sociedad se manifiesta en el tratamiento que ésta ofrece a sus ciudadanos condenados a penas de cárcel. Me permito añadir que el grado de conciencia social de un gobierno se expresa también en su política penitenciaria.

\section{REFERENCIAS BIBLIOGRÁFICAS Y DOCUMENTALES}

Aparicio Pérez, M.A. (2010), “Comentari a la sentencia 31/2010. Sobre el Poder Judicial”, Revista Catalana de Dret Públic (Especial Sentència 31/2010 del Tribunal Constitucional sobre l'Estatut d'autonomia de Catalunya de 2006). Versión cas- 
tellana accesible en: <http://www2o.gencat.cat/docs/eapc/Home/Publicacions/ Varia/Especial\%20Sentencia\%20Estatut/documents/especial_estatuto_es.pdf $>$.

Cabellos Espiérrez, M.A. (2010), "Poder Judicial i model d'estat ē la sentēncia sobre l'Estatut d'autonomia de Catalunya", Revista Catalana de Dret Públic (Especial Sentència 31/2010 del Tribunal Constitucional sobre l'Estatut d'autonomia de Catalunya de 2006). Versión castellana accesible en: <http://www2o.gencat.cat/ docs/eapc/Home/Publicacions/Varia/Especial\%20Sentencia\%20Estatut/documents/especial_estatuto_es.pdf>.

Generalitat de Catalunya, Departament de Justícia (2006), Trenta mesos d'acció de govern de justicia 2004, 2005, 2006: Barcelona (existe también edición en castellano). Disponible on-line: <http://www.gencat.cat/justicia/doc/doc_17819863_1. pdf>.

Generalitat de Catalunya, Departament de Justícia (2005), Llibre Verd de l'Administració de Justícia a Catalunya. Documents de Treball. Barcelona (existe también traducción al castellano editada en 2006). Disponible on-line: <http://www20.gencat. cat/docs/Adjucat/Documents/ARXIUS/doc_12074910_1.pdf $>$.

Vallès, J.M. (2008), Una agenda imperfecta: amb Maragall i el projecte de canvi. Barcelona: Edicions 62, 431 págs.

Recibido: 16 de marzo de 2011

Aceptado: 24 de abril de 2011 